\title{
Pourquoi filmer sa culture? Rituel et patrimonialisation en Amazonie brésilienne
}

Why film one's culture? Ritual as patrimony in Brazilian Amazonia

Por que filmar sua cultura? Ritual e patrimonialização na Amazônia brasileira

Chloé Nahum-Claudel, Nathalie Pétesch et Cédric Yvinec

\section{CpenEdition}

\section{Journals}

Édition électronique

URL : https://journals.openedition.org/jsa/15153

DOI : 10.4000/jsa. 15153

ISSN : $1957-7842$

Éditeur

Société des américanistes

Édition imprimée

Date de publication : 15 décembre 2017

Pagination : 47-80

ISSN : 0037-9174

Référence électronique

Chloé Nahum-Claudel, Nathalie Pétesch et Cédric Yvinec, « Pourquoi filmer sa culture ? Rituel et patrimonialisation en Amazonie brésilienne », Journal de la Société des américanistes [En ligne], 103-2 2017, mis en ligne le 15 décembre 2017, consulté le 28 septembre 2022. URL : http:// journals.openedition.org/jsa/15153 ; DOI : https://doi.org/10.4000/jsa.15153 


\title{
Pourquoi filmer sa culture? Rituel et patrimonialisation en Amazonie brésilienne
}

\author{
Chloé Nahum-Claudel, Nathalie Pétesch et Cédric Yvinec *
}

Cet article propose une étude détaillée de trois cas ethnographiques (Karajá, Enawenê-nawê, Suruí du Rondônia) dans lesquels sont produites des vidéos prétendant montrer la « culture » indigène, à travers la mise en spectacle de rituels collectifs. Nous examinons les raisons du choix de ces rituels comme incarnation de la culture, les enjeux politiques et symboliques de la mise en spectacle de la culture, les modalités de la production d'une image de soi, le choix de spectateurs pour cette culture filmée et les jeux de dévoilement et de dissimulation des savoirs rituels. Nous montrons ainsi que, dans le cadre des relations avec la société brésilienne et internationale, la patrimonialisation de la culture s'insère dans la dynamique d'intégration de l'altérité qui a toujours été le moteur de la reproduction des sociétés amazoniennes dans leurs interrelations. [Mots-clés: Karajá, Enawenê-nawê, Suruí du Rondônia, patrimonialisation, culture, vidéo, rituel, spectacle.]

Why film one's culture? Ritual as patrimony in Brazilian Amazonia. This article examines three detailed case studies (Karajá, Enawenê-nawê, Suruí of Rondônia) in which films of collective and spectacular ritual are produced as a means to display Amazonian indigenous "culture". The article examines the reasons for the choice of particular rituals as the incarnation of culture; the political and symbolic implications of the performance of culture; the modalities through which films are produced; the choice of spectators for this culture-on-film and the play of revelation and concealment of ritual knowledge which the filmic media enables. The creation of cultural patrimony, which occurs within the framework of relations with Brazilian and international society, fits into a key dynamic of Amazonian social reproduction and inter-ethnic relations, that is, the drive to integrate alterity. [Keywords: Karajá, Enawenê-nawê, Suruí of Rondônia, patrimonialization, culture, video, ritual, spectacle.]

Por que filmar sua cultura? Ritual e patrimonialização na Amazônia brasileira. Este artigo analisa três casos etnográficos (Karajá, Enawenê-nawê, Suruí do Rondônia)

*C. Nahum-Claudel : Pembroke College, University of Cambridge [cnahumclaudel@gmail. com]; N. Pétesch: Centre EREA du LESC, université Paris-Nanterre [nathalie.petesch@ orange.fr]; C. Yvinec: Mondes américains-CRBC, CNRS, Paris [cedric.yvinec@ehess.fr]. 
de produção de vídeos que pretendem mostrar a "cultura" indígena na forma de rituais coletivos. $\mathrm{O}$ artigo pesquisa as razões da escolha destes rituais para incarnar a cultura, os problemas políticos e simbólicos da encenação da cultura, as modalidades da produção de uma auto-imagem, a escolha dos espectadores da cultura filmada, e os jogos de revelação e ocultação dos saberes rituais. Assim o artigo mostra que, no quadro das relações com a sociedade brasileira e internacional, a patrimonialização da cultura continua a dinâmica de integração da alteridade que sempre foi o motor da reprodução das sociedades amazônicas nas relações entre elas. [Palavras chave: Karajá, Enawenê-nawê, Suruí do Rondônia, patrimonialização, cultura, vídeo, ritual, espetáculo.]

La dynamique de patrimonialisation de la culture affecte aujourd'hui la grande majorité des sociétés indiennes des Basses Terres d'Amérique du Sud. Ce mouvement indigène répond actuellement à des définitions légales, nationales et internationales de la culture et du patrimoine. En effet depuis 2003 une convention de l'Unesco prétend garantir la sauvegarde du patrimoine culturel immatériel de toute communauté humaine à travers le monde. Cependant en Amazonie cette dynamique était née antérieurement à l'intervention de ces organismes internationaux et, depuis ses débuts, les enjeux qui l'animent ont profondément évolué. Ainsi au Brésil, la démonstration, par les populations indigènes, de la possession d'une «culture » spécifique était devenue à la fin des années 1970 une nécessité politique, contre la prétention de l’État à l'assimilation des Indiens et à la négation de leurs droits, au premier chef fonciers (Ramos 1994; Jackson et Warren 2005; Graham et Penny 2014). Aujourd'hui, même si ces droits constitutionnels ne sont souvent pas respectés (Ramos 1998), les terres de nombreux groupes - dont ceux étudiés dans cet article - sont officiellement reconnues et délimitées. Néanmoins aujourd'hui les communautés de ces territoires se retrouvent à devoir dialoguer avec des partenaires qui présument que, dans la mesure où leurs interlocuteurs sont des indigènes, ceux-ci disposent, sous une forme ou sous une autre - ornements corporels, danses, chants, « chamanisme », etc. - de quelque chose susceptible d'être qualifié de « culture ». Au Brésil, ces partenaires sont non seulement des ONG indigénistes ou des institutions étatiques chargés des affaires indiennes, la Funai (Fundação Nacional do Índio) et de son antenne culturelle, le Museu do Índio, mais aussi des organismes responsables de la gestion du patrimoine, notamment l'Iphan (Instituto do Patrimônio Histórico e Artístico Nacional), avec lequel les communautés indiennes sont incitées à collaborer dans la sauvegarde de leur tradition indigène, en tant que partie intégrante du patrimoine culturel brésilien. Ces divers partenaires tendent souvent à présenter la perte de la « culture » d'un groupe comme une menace qui pourrait mettre en danger ses droits ou son accès à certaines ressources privées ou publiques - dans le cas des ONG, ce discours reflète la nécessité de se financer en se fondant sur une problématique bien identifiable sur le marché de la charité publique ou privée, 
la préservation des « cultures » en étant une. Or pour se prémunir contre, sinon la perte elle-même, du moins la réputation de perte de culture, il convient que la population en question réussisse à identifier une activité où s'incarne sa culture et à l'exposer à des regards extérieurs. Les groupes qui ont abandonné les pratiques incarnant leur culture risquent d'être stigmatisés comme des « ex-primitifs» (Bessire 2014) autant par leurs voisins indigènes, que par les agences gouvernementales et les ONG. Cette figure est en effet un épouvantail face auquel les trois groupes ici considérés s'efforcent de démontrer leur vitalité culturelle, en s'engageant avec enthousiasme dans divers projets permettant de prendre part à l'économie morale de la culture qui s'est mise en place au Brésil.

En parallèle avec la routinisation de cette économie morale de la culture, les angles d'analyse anthropologique ont considérablement évolué au sujet de cette dynamique historique de définition, d'exposition et d'appropriation d'une « culture » propre à chaque groupe. Dans les années 1980-1990 deux questions orientaient principalement les réflexions. L'une était d'ordre politique et tactique ${ }^{1}$ : la présentation des Indiens sous l'angle de la différence culturelle, souvent de manière très réductrice, était-elle efficace pour défendre leur droits et leur identité à long terme? L'autre portait sur les effets de la mise en spectacle de la culture ${ }^{2}$ : en engageant les Indiens à préserver certaines pratiques sous forme d'enregistrement audio ou vidéo, ne risquait-on pas de dénaturer ces mêmes pratiques et de saper leur vitalité propre? Le questionnement s'est ensuite déplacé à partir des années 2000 vers le regard indigène portés sur ces processus, pour examiner les concepts susceptibles de correspondre à la notion occidentale de culture. Certaines analyses, comparatives, comme celle de M. Carneiro da Cunha (2010), ont émis l'hypothèse que ces processus de patrimonialisation conduisent les Indiens à instaurer une distinction implicite entre, d'une part, une « culture en soi », vécue dans l'entre-soi communautaire et incarnée par un mode de vie et un éthos social qui servent de marqueurs identitaires dans l'environnement ethnique proche, et d'autre part, une «culture pour soi », qui doit être mise en scène et en valeur, de manière à authentifier son indianité aux yeux des non-indigènes. D'autres analyses, souvent appuyées sur des cas très particuliers, comme celle de C. Fausto (2011) sur le système inter-ethnique du Haut-Xingu, soulignent au contraire que certaines pratiques rituelles jouaient déjà ce rôle de « culture pour soi » dans les relations entre groupes indiens.

C'est de cette question que part l'analyse que nous proposons ici. Comment trois groupes indigènes, les Karajá, les Enawenê-Nawê et les Suruí du Rondônia, qui vivent dans un même cadre national, celui du Brésil, tentent-ils de légitimer leur vie culturelle vis-à-vis de publics spécifiques à chaque cas, mais

1. Voir Ramos (1994) ou Conklin $(1997,2002)$.

2. Voir Turner (1992) ou, pour des discussions extérieures à l'aire amazonienne, Ginsburg (1991), Weiner (1997) et Boyer (2006). 
toujours intéressés par le spectacle des cultures indigènes et résolus à investir des ressources conséquentes dans sa conservation? Confrontés à cette situation, quelle « culture » les Indiens choisissent-ils? Dans les trois cas ici comparés la culture recherchée a alors été trouvée dans des pratiques rituelles collectives se prêtant aisément à la mise en spectacle filmique - un des médias préférés au Brésil (Morgado 2014). L'examen des voies par lesquelles la notion de culture a été interprétée dans chaque groupe en fonction de trajectoires historiques spécifiques et d'enjeux politiques propres montre que ces cas de patrimonialisation ne peuvent être réduits ni à la figure de la rupture entre une « culture en soi » et une « culture pour soi », ni à celle de la continuité d'une dynamique traditionnelle d'invention et d'extériorisation culturelle. Nous montrons qu'un processus concrètement très similaire, la mise en spectacle de rites d'échange entre sous-groupes, peut être utilisé de manière très différente, afin de nouer des relations politiques et symboliques avec différents types d'acteurs extérieurs et de reconfigurer en conséquence les relations internes au groupe. Dans le même temps, nous montrons que les trois rituels - rite d'initiation, rituel de flûtes, fête de boisson - se révèlent inégalement aptes à se couler dans les contraintes et transformations qu'impose cette mise en spectacle.

Dans ces trois cas, la notion de « patrimonialisation » renvoie à des formes de reconnaissance et des degrés d'institutionnalisation de la culture bien différents. Chez les Enawenê-Nawê ce processus s'est développé jusqu'à son stade le plus officiel et juridique, à travers l'inscription du rituel yaokwa dans des catégories nationales et internationales définies par l'Iphan et l'Unesco, ce qui implique non seulement des mesures de sauvegarde, mais aussi tout un suivi bureaucratique. Chez les Karajá, dont l'art de la céramique a déjà été inscrit au registre de l'Iphan, c'est un projet de sauvegarde culturelle mené en collaboration avec un musée français que nous examinons. Chez les Suruí, il ne s'agit (encore?) que d'une mise en spectacle vidéo à destination d'un public étranger. Cependant, ces différences paraissent surtout le fruit de hasards historiques - insertion dans tel ou tel réseau indigéniste, intérêt de telle ou telle institution. Elles ne doivent pas masquer que, du point de vue des Indiens, il s'agit toujours d'un même mouvement présentant de manière spectaculaire des pratiques supposées définir à la fois leur indianité générique et leur identité ethnique spécifique aux yeux des étrangers. En outre, ces pratiques correspondent dans chaque cas à un grand nombre des incarnations du patrimoine culturel immatériel qu'énumère l'article 2 de la convention de 2003 de 1'Unesco: « les traditions et expressions orales [...]; les arts du spectacle; les pratiques sociales, rituels et événements festifs; les connaissances et pratiques concernant la nature et l'univers; les savoir-faire liés à l'artisanat traditionnel ». Cet article ne discute donc nullement les définitions du patrimoine, qui ne sont pas questionnées par nos cas ethnographiques. L'analyse se concentrera sur les enjeux symboliques, interactionnels et sociologiques qu'implique, pour ces trois sociétés amérindiennes, la présentation de leur culture sous forme filmique; 
les dimensions formelles, techniques, stylistiques ou esthétiques de ces vidéos comme produits finis ou de leur tournage, ne seront pas abordées ici, aucun des trois auteurs n'étant spécialiste d'anthropologie visuelle ou doté de la moindre compétence cinématographique.

Les Karajá comptent environ 3000 personnes, vivant sur plusieurs États du Brésil central (Tocantins, Mato Grosso, Goiás et Pará) et parlant une langue de la famille gé-bororo. Leur habitat est constitué d'une vingtaine de villages situés sur les rives du Rio Araguaia. Leur contact avec les Blancs remonte au XVII ${ }^{\mathrm{e}}$ siècle. Les Karajá ont ainsi subi les tentatives d'évangélisation des missionnaires jésuites, dominicains puis protestants et ont dû résister à des vagues successives de colonisation agro-pastorale. Au fil du temps, ils ont réussi à se maintenir sur une partie de leur territoire, tout en s'intégrant dans le tissu économique de la région à travers le commerce de leur artisanat et des produits de la pêche et de l'horticulture, complété par des emplois salariés. En 2010, ils ont obtenu la collaboration du Muséum d'histoire naturelle de Toulouse (MHNT) par l'intermédiaire de l'association toulousaine Jabiru Prod qui menait des projets de revalorisation culturelle dans la région voisine du Haut-Xingu. Cette collaboration a notamment porté sur le tournage d'un film concernant le rituel d'initiation masculine. Le MHNT demandant l'expertise d'un anthropologue, les Karajá ont suggéré de faire appel à Nathalie Pétesch qui avait séjourné chez eux à plusieurs reprises. Les Enawenê-nawê sont un groupe comptant aujourd'hui environ 700 individus, parlant une langue de la famille arawak. Ils vivent au nord-ouest du Mato Grosso, sur le Rio Iquê. Contactés en 1974 par des jésuites, alors qu'ils étaient moins de 100, leurs relations avec la société brésilienne sont restées limitées et contrôlées par les missionnaires puis par l'association indigéniste Operação Amazônia Nativa (OPAN) jusqu'à la fin des années 1990. À l'initiative de cette organisation qui travaille avec les Enawenê-nawê depuis le contact, leur cycle rituel yaokwa a été inscrit au registre de l'Iphan en 2010 et à celui de 1'Unesco en $2011^{3}$. Chloé Nahum-Claudel menait des recherches de terrain pour son doctorat au moment où le film (Carelli et Campoli 2009) qui a constitué la pièce centrale de l'inventaire de l'Iphan et de l'Unesco était en tournage. Sans y participer, elle a donc pu observer la réalisation de cet inventaire (Jakubazko 2010), pour lequel d'autres anthropologues fournissaient leur expertise. Les Suruí, qui comptent aujourd'hui environ 1200 individus, parlent une langue de la famille tupi-mondé et vivent au Rondônia, à proximité de la ville de Cacoal. Contactés par la Funai en 1969, ils ont été confrontés à un choc épidémique qui les réduisit à moins de 200 individus dans les années 1970, à des plans de colonisation agricole, et à l'action de missionnaires protestants. Convertis à l'évangélisme,

3. Voir http://www.unesco.org/culture/ich/en/USL/yaokwa-the-enawene-nawe-peoples-ritual-for-the-maintenance-of-social-and-cosmic-order-00521 (consulté le 23/10/2017). 
vivant de cultures de rente et du trafic de bois depuis les années 1980, ils se sont tournés dans les années 2000 vers l'économie des projets écologistes. Aucune de leurs pratiques n'a encore fait l'objet d'une inscription sur un registre patrimonial officiel, bien qu'ils documentent régulièrement un rituel de boisson par des vidéos qui, diffusées sur Youtube, s'inscrivent dans une dynamique d'incorporation du regard étranger sur leurs fêtes. Cédric Yvinec a participé à une fête filmée en 2005, et aux préparatifs d'une autre en 2007, sans jamais être sollicité par les ONG organisatrices du tournage 4 .

\section{Comment trouver sa « culture »?}

Parce qu'elle exige de nommer une pratique ou un savoir, de les circonscrire et de les exhiber, la mise en spectacle nécessite de sélectionner certains actes comme emblématiques de la culture du groupe. Cette sélection s'appuie sur l'interprétation indigène de la notion de culture que véhiculent les diverses catégories de Blancs avec lesquels les Indiens interagissent - muséologues, membres d'organisations indigénistes, fonctionnaires de la Funai, colons, instituteurs, personnels de santé, touristes, journalistes, anthropologues, etc.

Le cas des Karajá illustre une situation où l'influence du regard extérieur sur la «culture » fut importante. Dès les années 1940, ceux-ci ont été parmi les premiers groupes utilisés comme vitrine indigène de l'Amazonie brésilienne par les autorités gouvernementales. Observés, photographiés, filmés dans le cadre enchanteur des plages de l'Araguaia, c'était alors un visage idéalisé du « Naturel» amérindien qu'ils étaient supposés incarner à travers leur art de la céramique, leur ornementation corporelle et le mystère de leurs danses de masques. Dans les années 1980, l'alcoolisme et les dissensions internes altérèrent cette image auprès des Blancs, mais aussi de leurs voisins indigènes. Ceux-ci les reléguèrent dans la catégorie des Indiens « sans culture » (índios sem cultura), qui abandonnaient leurs terres aux colons. Parmi leurs voisins, les Kayapó étaient alors engagés, aux côtés de personnalités du show business, dans une lutte politique pour la défense de leur territoire, alors que les groupes du Haut-Xingu étaient depuis plusieurs années les meilleurs pourvoyeurs de

4. L'ethnographie des Karajá a été réalisée par Nathalie Pétesch pendant deux ans entre 1985 et 1990, puis en 2010-2011. Dans cet article, nous parlons uniquement des Karajá au sens strict (ou Karajá de l'amont), distincts des Xambioá (ou Karajá de l'aval) et des Javaé. L'ethnographie des Enawenê-nawê est l'œuvre de Chloé Nahum-Claudel et a été réalisée, pour l'essentiel, en 2008-2009. L'ethnographie des Suruí, par Cédric Yvinec, s'appuie sur environ 18 mois de terrain, en 2005-2007, puis 2013 et 2015. Pour des informations ethnographiques plus détaillées sur ces rituels, qui sont au cœur des travaux des trois auteurs, voir Pétesch 2000, Nahum-Claudel (2017) et Yvinec 2011. Cet article est le fruit d'une journée d'étude, «Rituel et patrimonialisation », organisée dans le cadre du projet ANR Fabriq'Am (Fabrique des patrimoines en Amérique indigène, ANR-12-CULT-005) en 2014. 
spectacles rituels amazoniens auprès des médias et des cinéastes du monde entier, sous l'impulsion des frères Villas-Boas, créateurs du Parc Indigène du $\mathrm{Xingu}^{5}$. Ces deux ensembles ethniques utilisaient les Karajá comme repoussoir pour mettre en valeur leur propre vitalité ethnique et culturelle. Face à cette vision dévalorisante, au tournant du $\mathrm{XXI}^{\mathrm{e}}$ siècle, les Karajá se lancèrent dans une démarche de réhabilitation et de sauvegarde culturelle. Celle-ci débuta par des actions administratives et juridiques pour la récupération des terres laissées aux mains des colons, principalement dans l'île du Bananal, le cœur de leur territoire. Bientôt des projets culturels se mirent en place ${ }^{6}$, tous tournés vers le regard de Blancs proches ou lointains: d'abord par la création d'un centre culturel dans la petite ville brésilienne de São Félix do Araguaia, dont l'objectif est de faire connaître et de commercialiser la production artistique karajá ; puis par l'inscription de leurs « pratiques et savoirs associés à la confection de figurines en céramique (ritxòkò) » au registre du patrimoine culturel immatériel de 1'Iphan, achevée en 2012; enfin par la collaboration du village de Santa Isabel (Hawalo mahadu) avec le MHNT dans l'enregistrement audio et vidéo des principaux éléments du patrimoine culturel. Celle-ci a consisté à former plusieurs jeunes gens à ces différentes techniques et a abouti à la production de deux films: Bero hoky mahadu (Guiraud 2011), sur le rituel d'initiation, et Ritxoko (Guiraud 2012), sur la confection de la céramique. Aujourd'hui, cette activité filmique se poursuit dans plusieurs villages karajá.

Dans cette collaboration, le rituel d'initiation masculine heto hokã fut le premier objet à être filmé par les Karajá parmi les incarnations de la notion de cultura, un terme repris du portugais au sens bien plus restreint de « fête », « spectacle $\rangle^{7}$. Pourquoi ce choix? Par son déploiement à la fois sociologique et cosmologique, le heto hokã constitue le principal rituel du cycle cérémoniel de ce peuple indigène. Contrairement aux rituels agraires ou à celui des esprits des ennemis tués à la guerre, le heto hokã est intercommunautaire, mobilisant l'ensemble d'un village et incluant la participation d'autres villages. La présence de la plupart des êtres surnaturels peuplant le panthéon karajá est également requise, incarnés ou non par des masques. L'union sociale et

5. Ces processus, et notamment leurs enjeux en matière de politique identitaire, ont déjà été amplement documentés et analysés dans le cas des Kayapó (voir Turner 1991, 1992; Gordon 2006) et dans celui du Haut-Xingu (voir de Vienne et Allard 2005; Barcelos Neto 2006; Fausto 2011).

6 . Il ne faut pas négliger par ailleurs la dimension financière de cette dynamique patrimoniale; monter un projet culturel permet aujourd'hui de lever plus facilement des fonds et de nouer plus de partenariats qu'une action dans le domaine agro-forestier ou sanitaire.

7. La locution donnée par les Karajá en réponse à la question « Comment exprimer en langue indigène la notion de cultura? », Iny bydedyynana, « mode de vie karajá », possède un sens beaucoup plus vaste (ce concept s'applique aux humains comme aux non-humains). Elle n'est quasiment jamais utilisée pour se référer spécifiquement aux activités mises en spectacle. 
cosmique ainsi réalisée atteste de la force et de la vitalité du groupe ethnique. La préparation du rituel court sur plusieurs semaines afin d'assurer la collecte de la nourriture, le montage des structures nécessaires sur la place du village, ainsi que la confection des ornements corporels et des objets cérémoniels. La partie intercommunautaire du rituel ne dure que deux à trois jours, mais elle est lourde d'enjeux politiques: la fête doit être à la hauteur de la réputation du village invitant, par l'abondance de la nourriture, par le bon déroulement des différentes phases rituelles, par la qualité et l'innovation des chants et des danses, ainsi que par la générosité des parents proches des jeunes initiés à l'égard des parents éloignés qui ont apporté leur contribution dans la réalisation de la cérémonie. De fait, le heto hokã s'apparente à un potlatch, où don et contre-don sont des défis scrupuleusement mesurés. Dans la représentation des entités spirituelles convoquées pour l'initiation des jeunes garçons, les membres des villages invités incarnent l'altérité et viennent défier leurs hôtes dans des luttes corporelles et autres rituels d'opposition. La communauté invitante doit pouvoir à la fois sortir victorieuse de ces assauts répétés, mais aussi rétribuer ces interventions de nature spirituelle à un niveau équivalent ou supérieur à ce qui a été fait auparavant par les autres villages.

Lorsque le rituel fut filmé en 2010, il était certes structurellement identique à ceux observés par Nathalie Pétesch une vingtaine d'années auparavant. Les protagonistes étaient les mêmes : les villages karajá invités face au village hôte. Cependant leurs évolutions sur la place cérémonielle étaient observées par de nombreux visiteurs non-indigènes conviés par les leaders karajá : habitants des villes les plus proches, commerçants, élus locaux ou régionaux, fonctionnaires et universitaires venus de Brasília, la plupart munis d'appareils photos ou de caméras. Loin de se dérober à ces regards étrangers, comme c'était le cas dans les années 1980, les Karajá de tous âges exhibaient leurs parures corporelles dont l'abondance et la variété ne manquaient pas d'étonner. Ainsi, de magnifiques coiffes cérémonielles, censées être l'apanage de quelques familles de chefs et dont l'usage avait été abandonné, étaient utilisées par tous les jeunes garçons en passe de subir leur initiation (voir Figure 1). En plus de cette esthétisation, une place accrue était consacrée aux jeux d'opposition, car ces pratiques à caractère ludique sont très appréciées par les visiteurs non-indigènes, à qui on donnait même la possibilité d'y participer.

Tout en respectant un déroulement plus ou moins traditionnel, le heto hokã tend donc à accentuer son caractère ostentatoire et à renforcer ses aspects esthétiques et ludiques, en mettant en valeur la beauté des corps et des masques, l'animation des danses et des jeux, en vue de créer un spectacle qui puisse être apprécié, audelà des frontières ethniques, par un regard extérieur. Rivalisant ainsi avec ceux du Haut-Xingu et seul rituel du corpus cérémoniel susceptible d'accepter une participation non-indigène, le heto hokã apparaît aux yeux des Karajá comme la pratique culturelle emblématique de leur groupe, justifiant sa sélection au moment 


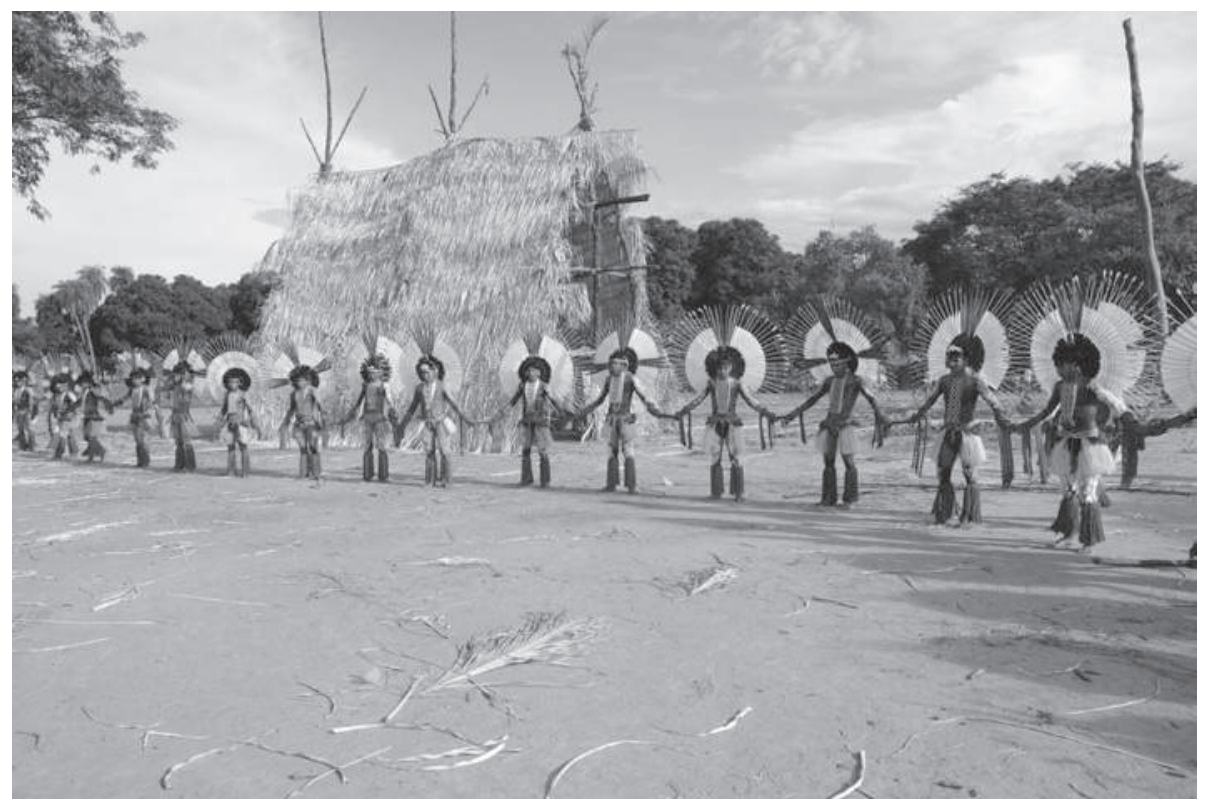

Fig. 1 - Rituel d'initiation karajá (photo: Serge Guiraud).

du tournage. En même temps, ce regard extérieur qui détermine ce qui relève ou non de la culture peut être douloureusement ressenti par les Karajá. Tantôt il est décrit comme réducteur: « Les Blancs, remarqua un informateur de Nathalie Pétesch en 2010, ne s'intéressent qu'à la fête karajá; ils nous rendent visite seulement quand ils savent que les masques sont sortis. » Tantôt la patrimonialisation apparaît comme le signe d'une dépossession, pour les communautés karajá qui ne sont plus détentrices de ces objets de « culture », pour les villages où les rituels collectifs ont disparu: "C'est triste, dit l'un des jeunes informateurs karajá de E. Soares Nunes (2009), moi qui suis né ici, je n'ai jamais connu la culture; tout ce que je sais de la fête karajá, c'est ce que l'on m'en a dit. »

Par contraste avec le travail de revalorisation fait par les Karajá, la sélection du rituel yaokwa comme incarnation de leur «culture » résulte, chez les Enawenê-nawê, d'une convergence spontanée entre leurs perceptions et celles des Blancs. La saison rituelle nommée yaokwa (depuis la récolte du maïs vert en décembre jusqu'aux nouvelles plantation de manioc en juin-juillet) est la phase la plus importante au sein du cycle annuel. Or par contraste avec d'autres rituels du cycle - notamment le saluma, dans lequel, dansant armes en main tout en improvisant des chants, les hommes incarnent des guerriers ancestraux et exaltent leur puissance prédatrice pour affronter des étrangers - le yaokwa célèbre la vie civilisée, la fertilité et la vitalité, autour des essarts de manioc et des barrages de pêche. Les danses, les flûtes et les chants au contenu fixe 
du yaokwa se réfèrent à une ancestralité archétypale; ce rituel met en scène les actions mythologiques du démiurge, il vise à pacifier les esprits prédateurs et permet de recréer périodiquement la communauté en réincorporant régulièrement les affins. Pendant les sept mois saison du yaokwa, un orchestre masculin (instruments à vent, sonnailles) joue quotidiennement sur la place centrale du village (voir Figure 2), qui est aussi le lieu de festins, d'échanges et d'exposition des produits de travaux collectifs (pêche, horticulture, vannerie, collecte de bois de chauffe, préparation de boissons). La fréquence de l'activité cérémonielle sur la place centrale du village a frappé les indigénistes dès les premiers contacts pacifiques en 1974 - éclipsant d'autres stéréotypes de l'Indien, comme le guerrier ou le chamane (Conklin 2002), et d'autres incarnations de la culture, comme le récit mythologique (Hugh-Jones 2010). Les performances chorégraphiques des danseurs du yaokwa arborant ornements et flûtes sont décrites par les Enawenê-nawê comme awale, "belles »; ce terme a un sens à la fois esthétique et moral, et telle est l'impression que le spectacle du rituel semble avoir fait sur tous les observateurs étrangers, depuis les premiers jésuites (Lisbôa 1985). Les termes portugais ritual et cultura ont très rapidement été intégrés au lexique enawenê-nawê, comme l'atteste leur fréquence dans le

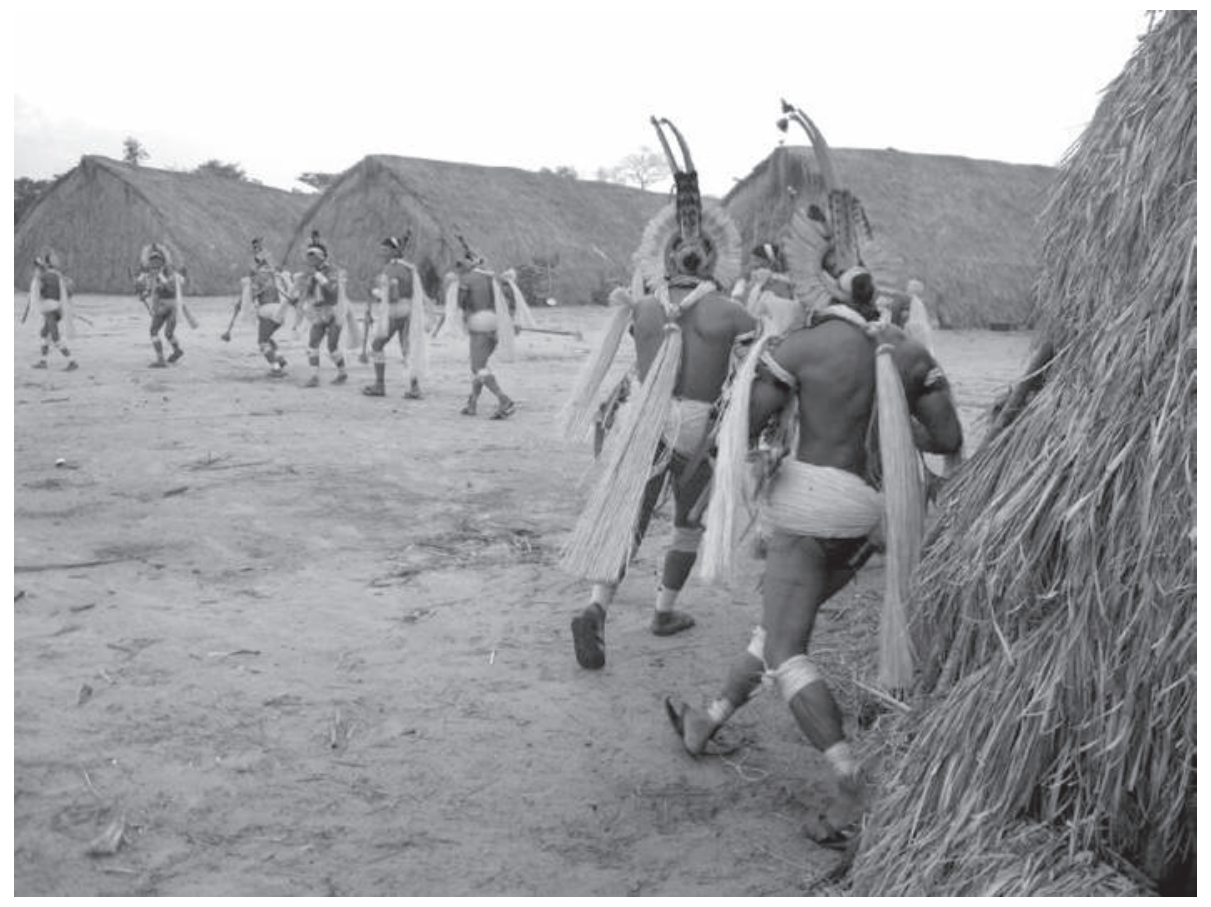

Fig. 2 - Orchestre de flûtes sur la place du village enawenênawê (photo: Chloé Nahum-Claudel). 
journal du jésuite Vicente Cañas qui vécut chez eux dans les années 1980 (Cañas s.d.). Aujourd'hui on peut souvent entendre des danseurs dire avec satisfaction à l'anthropologue ritual nato, « je suis le rituel », ou déclarer avec irritation après une rencontre décevante avec des fonctionnaires de la Funai à Brasilia wi-cultura-ne hotaka dema, « ils disent que nous oublions notre culture [en achetant des biens manufacturés] ». Les Enawenê-nawê ont adopté l'idée que la culture est un bien rare, dont la possession peut être quantifiée et qu'on peut utiliser ou perdre. Les Enawenê-nawê ont l'habitude de se comparer aux Indiens du Haut-Xingu en énumérant les items de culture (chants, rituels) qu'ils possèdent respectivement. En outre, par les ressources monétaires que le yao$k w a$ requiert aujourd'hui - pour l'achat de moteurs hors-bord et de carburant pour les expéditions de pêche, de tronçonneuses pour l'ouverture des essarts, de casseroles pour les festins - le yaokwa légitime les demandes de subsides auprès d'organismes étatiques, aide que les Enawenê-nawê ont appris à solliciter en jouant de toutes les complexités de la bureaucratie brésilienne (voir Nahum-Claudel 2012; Nahum-Claudel 2016). Dès lors, puisque la réalisation du yaokwa reçoit des soutiens financiers divers et, en plus, attire régulièrement l'attention d'anthropologues, de médias audiovisuels, de journalistes et d'ONG, les Enawenê-nawê ont conscience d'être valorisés au Brésil et à l'étranger en tant qu'Indiens dotés d'une « culture authentique ». Le regard et l'action des Blancs sur le rituel comme manifestation de la «culture » rencontrent donc ici spontanément la définition du yaokwa comme expression des valeurs de la vie sociale idéale, pacifiée et raffinée.

Le cas des Suruí illustre enfin une situation où la définition de la « culture » s'est faite indépendamment du regard des Blancs, voire contre celui-ci, bien que l'objet sélectionné soit en fin de compte un rituel très semblable à ceux choisis par les Enawenê-nawê et les Karajá. En effet, lorsque les Suruí ont à définir leur « culture ", c'est toujours vers un système cérémoniel bien précis qu'ils se tournent, l'ensemble des différents rites de boisson. Au premier abord, ces activités sont pourtant considérées par nombre de Blancs avec un léger dégoût - en raison de la pré-mastication des aliments par les femmes et des vomissements - voire avec une franche hostilité - en raison de l'ivresse, grave péché aux yeux des missionnaires protestants, qui furent les principaux agents du déclin de ces pratiques dans les années 1990. Cette association entre « culture » et rituel s'enracine en fait dans la conception que les Suruí ont de la première notion. En réaction aux accusations d'acculturation, du fait de l'abandon des principaux insignes de l'indianité aux yeux des Blancs - nudité, habitation collective de type maloca, pratique intensive de la chasse - il est fréquemment affirmé que « nous, Suruí, avons deux cultures » et que ces « cultures » peuvent être « utilisées » alternativement, selon les jours, voire les moments de la journée. «Utiliser la culture du Blanc », ce peut être circuler en ville au volant d'un pick-up, vêtu de son costume de sortie - chemise, jean et mocassins - et négocier l'achat de 
riz et de sodas, en portugais. Peut-être le soir même reviendra-t-on au village « utiliser la culture de l'Indien » en se peignant le corps au genipa, consommant de la bière de maïs, en chantant en suruí devant ses parents et alliés qu'on aura rassemblés grâce aux instruments de la « culture du Blanc » mobilisée quelques heures plus tôt. Un homme trop peu lusophone, trop peu instruit (scolairement) ou trop malhabile dans les activités rémunératrices (caféiculture, trafic de bois) ne pourra « utiliser la culture du Blanc », quand un mauvais chanteur suruí, un mauvais essarteur ou un célibataire mal nourri et mal orné ne pourront « utiliser la culture de l'Indien ». S'il est possible d'avoir deux « cultures », il arrive donc qu'on n'en maîtrise aucune. Car cette conception de la « culture » renvoie directement à la locution suruí que le substantif portugais est supposé traduire: same, « la manière d'être » d'un individu ou d'un collectif. Or, lorsqu'elle s'applique à un clan ou à l'ethnie suruí, cette locution prend une nuance normative et la «culture » désigne alors les comportements les plus valorisés au sein de ce groupe - elle est d'ailleurs parfois traduite par « loi » (lei). Aussi la « culture suruí », en tant que « manière d'être suruí », est-elle associée aux activités qui, dans la société suruí d'avant le contact, étaient caractéristiques des hommes forts, c'est-à-dire la polygamie, la guerre, la production horticole et ornementale, et les rites de boisson.

La pacification interdisant le recours à la guerre et le poids des nouvelles activités économiques (cultures de rente, trafic de bois, emplois administratifs) détournant de la production de richesse traditionnelle, il ne reste donc que le rituel de boisson pour afficher sa possession de la « culture de l'Indien », en tant que « manière d'être propre aux (grands hommes) suruí ». Ce rite ne nécessite qu'une mobilisation ponctuelle des ressources horticoles et artisanales. Un individu doit rassembler des membres de son clan patrilinéaire et produire de la bière fermentée de maïs de patate ou d'igname en grande quantité. Il met alors ses alliés et ses affins au défi de l'ingurgiter publiquement, ce qu'ils ne peuvent faire sans vomir et tomber ivres-morts. En échange de la bière offerte, le producteur s'empare des flèches et des ornements corporels des buveurs, que ceux-ci ont eu soin de produire en quantité considérable. Les buveurs, sous l'effet de la bière, dansent et chantent des chants de leur composition. Autrefois cette relation rituelle pouvait se déployer dans un cycle s'étendant sur une année. Aujourd'hui, seule une fête ponctuelle est organisée - et quasiment toujours filmée (voir Figure 3). On choisit néanmoins la fête (mapi-ma-ih, « bière du mapi ») qui concluait autrefois le cycle et qui était, pour cette raison, la plus prestigieuse - elle permettait notamment à son promoteur de s'inscrire dans la liste des individus qui « avaient été mapi». Le choix de ce rituel comme manifestation de la « culture suruí » susceptible d'être présentée à des étrangers obéit donc ici à une logique strictement interne au groupe et se place dans le prolongement d'une tradition historique antérieure à la patrimonialisation. 


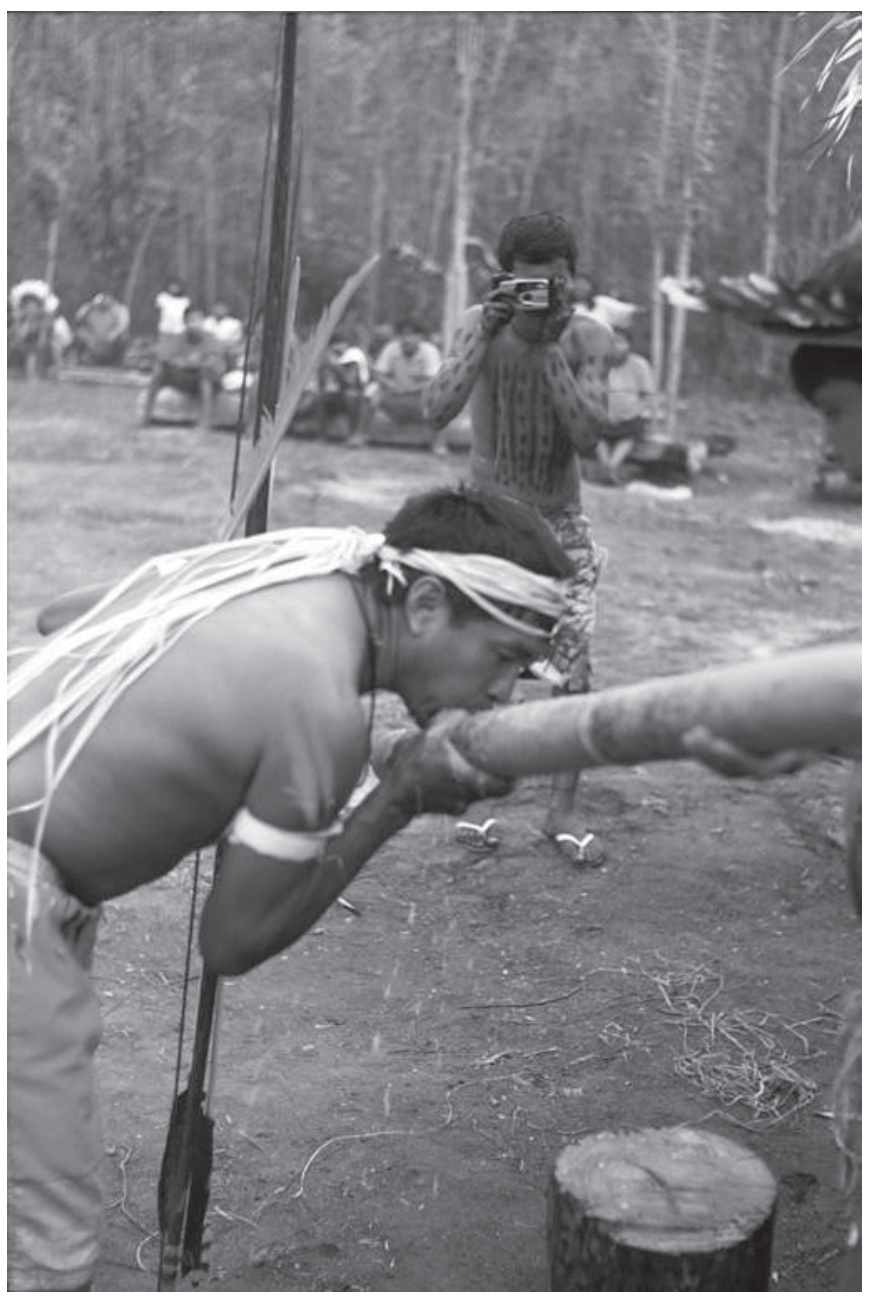

Fig. 3 - Adolescent Suruí photographiant la fête de boisson (photo: Cédric Yvinec).

C'est donc en fonction de logiques et d'enjeux contextuels très différents - allant d'un concept imposé de l'extérieur (Karajá) à une résistance s'appuyant sur une logique interne (Suruí) en passant par un accord spontané (Enawenê-nawê) - que les trois groupes considérés en sont arrivés à trouver la manifestation de leur « culture » dans des objets assez comparables: des activités ritualisées, publiques et collectives, impliquant un rapport dissymétrique entre des invitants et des invités, qui induit à divers niveaux une relation d'acteur à spectateur. Ces rituels présentent cependant des différences importantes, qui ne doivent pas être négligées pour comprendre les usages qui en sont fait lorsqu'on les filme pour y faire voir sa 
culture : la fête de boisson suruí, comme celles de nombreuses populations tupi, n'a jamais eu aucune dimension ésotérique, alors que cet aspect était (et reste) central dans les rituels enawenê-nawê et karajá. En effet, définir sa culture par des pratiques peu ou prou semblables, ne signifie cependant à l'utiliser pour répondre aux mêmes questions.

\section{Démontrer son authenticité ou son identité}

Pour démontrer publiquement qu'on possède une « culture », au sens qu'accordent à ce terme aussi bien les autorités patrimoniales (Iphan, Unesco, musées) que les organisations indigénistes, il convient de répondre à deux exigences, dont le poids relatif peut varier. La première est une exigence d'identité et de distinction : la « culture » doit être le propre du groupe ${ }^{8}$ la revendiquant et le différencier d'autres. La seconde porte sur l'embarrassante notion « d'authenticité »: la pratique documentée et éventuellement inscrite sur des registres patrimoniaux doit faire la preuve d'une certaine ancienneté, d'une relative stabilité et d'un faible degré de réflexivité (Fausto 2011, p. 191). En raison des différents contextes historiques et enjeux politiques présidant à la définition de leur « culture », les trois groupes considérés concilient différemment ces deux exigences.

Dans le cas des Karajá, accusés d'acculturation, la question de l'authenticité le dispute à celles de l'identité et de la distinction. Cette dernière est en effet centrale dans la région où vivent les Karajá : les relations interethniques, tant avec les Blancs qu'entre groupes indigènes, sont déjà structurées par la « culture », mesurée à la capacité à produire des rituels comme spectacles visuels à présenter aux Blancs, voire, dans certains cas (Haut-Xingu), aux autres groupes. L'incapacité à présenter ses rituels amène à se retrouver rangé dans la catégorie des «Indiens sans culture », y compris par les groupes voisins ${ }^{9}$. Aussi, pour modifier le regard critique trop longtemps posé sur eux et être capables de rivaliser avec les autres groupes indigènes de la région dans leur relation avec les Blancs, il est apparu nécessaire aux Karajá de se voir et de se donner à voir dans les médias nationaux et internationaux, ce qui nécessitait la construction d'un patrimoine culturel qui soit bien visible de l'extérieur, comme garant de leur identité ethnique. La valeur de l'image produite se mesurait à sa capacité

8. Se pose ici la question de la légitimité des individus ou des collectifs qui prétendent présenter la culture du groupe, et donc celle de la propriété des savoirs culturels et de leur transmission au sein et hors du groupe (voir de Vienne et Allard 2005). Dans les cas considérés ici, cet enjeu n'apparaît tantôt aucunement (Enawenê-nawê), tantôt uniquement de manière indirecte et sans jamais employer le langage de la propriété intellectuelle (Suruí, Karajá).

9. Ainsi quoique reconnus « maîtres du javari », l’une des plus importantes cérémonies du Haut-Xingu, dans la mesure où ils sont réputés avoir introduit ce rituel dans le système interethnique, les Trumai ont longtemps été accusés d'être " sans culture » par les autres groupes xinguano, parce qu'ils n'organisaient plus de rituels (de Vienne et Allard 2005). 
à rivaliser avec celles des voisins. Ainsi, en visionnant le film tourné en 2010 par l'équipe de cinéastes karajá, plusieurs individus ont déclaré avec une grande satisfaction que leur rituel était « aussi beau qu'un rituel du Xingu ». Cette urgence de la distinction a entraîné un double mouvement. D'une part, à l'échelle interethnique, depuis les années 1980, la compétition pour la reconnaissance culturelle s'est élargie et aiguisée, du fait de la capacité de certains groupes, les Kayapó au premier chef, à attirer à leurs démonstrations de culture des spectateurs lointains et prestigieux, comme des stars internationales - au prix d'un risque accru d'accusations d'inauthenticité et d'une standardisation de l'indianité (Conklin 1997). Dans ce contexte, la reconnaissance patrimoniale par des autorités officielles permet alors de préserver l'aspect distinctif de la culture du groupe. D'autre part, à l'échelle intraethnique, il se développe un mouvement symétrique d'accentuation des distinctions: une forme de «business patrimonial » tend à générer concurrence et surenchère, contribuant à accentuer les dissensions internes au sein du groupe karajá, plutôt qu'à favoriser sa cohésion dans la mise en œuvre d'un projet commun d'exhibition de la culture. Pour autant, cette exigence d'affirmation identitaire via la diffusion d'une image esthétisante n'exclut pas celle de l'authenticité culturelle, mais la complète en quelque sorte. En ce sens, le choix des figurines humaines de terre cuite (ritxòkò), visant à l'obtention d'une reconnaissance patrimoniale par des autorités officielles (Iphan), est révélateur. Cet art ancestral, dont l'originalité le distingue des autres pratiques céramistes amazoniennes, s'était vu peu à peu déprécié par sa conversion en principale monnaie d'échange dans le commerce des Karajá avec les Blancs locaux. Désormais inscrites au registre du patrimoine national brésilien, les ritxòkò font la fierté des céramistes karajá qui redoublent de créativité ${ }^{10}$ dans la confection de leurs pièces, lesquelles trouvent maintenant acquéreurs sur les marchés national et international. Ainsi la reconnaissance officielle du caractère authentique et original de ces « poupées » en terre cuite vient renforcer l'affirmation d'une identité culturelle karajá toute aussi vivante et singulière que celles des autres groupes indigènes du Brésil central.

Les Enawenê-nawê ont eux aussi affaire à des agents officiels dans la reconnaissance de leur culture, mais, à la différence des Karajá, ils ont une confiance absolue dans leur capacité à « gagner » toute épreuve de culture face à d'autres

10. L'originalité de cet art ancestral réside dans la fabrication de figurines humaines en céramique jadis destinées aux jeux des enfants. Dès les années 1950, la commercialisation de ces ritxòkò sur le marché brésilien a fait évoluer ces formes d'expression plastique pour les adapter aux canons esthétiques des consommateurs urbains. Les artisanes visent aussi à souligner la richesse de leur culture à travers la représentation de personnages et de scènes issus du corpus mythique et rituel, ou de la vie quotidienne. La créativité des céramistes continue à s'exprimer à la fois dans le style qui est propre à chacune et dans la diversité des sujets ou des thèmes représentés. Les créations les plus originales sont ensuite reprises par les autres céramistes. 
groupes indigènes - tout comme, disent certains, ils remportent toujours le concours de tir à la corde dans les « Jeux indigènes » organisés par la Funai. L'exigence de distinction n'est donc nullement problématique, puisque d'emblée résolue. Plus que la rivalité avec les autres cultures indigènes, c'est la relation avec l'État et l'opinion publique qui est pour eux cruciale. Le tournage opéré par l'ONG Vídeo nas Aldeias pour l'Iphan en 2009 avait pour objectif de sensibiliser les autorités aux effets néfastes de la construction de centrales hydroélectriques sur le cours supérieur du Rio Juruena, qui fragilisaient les ressources halieutiques nécessaires à la réalisation du yaokwa et menaçaient donc la vie, et bien sûr la « culture » enawenê-nawê. Ils espéraient qu'un documentaire produit en 2012 par TV Globo (Francisco 2012), chaîne jouissant d'une large audience dans le pays, conforterait leur réputation d'Indiens « authentiques » auprès du public brésilien. Les Enawenê-nawê étaient persuadés que le fait d'obtenir la reconnaissance, par un organe gouvernemental, du yaokwa comme pratique culturelle n'ayant jamais été abandonnée depuis le contact renforcerait leur position dans leur négociation avec ce même gouvernement qui soutenait la construction de centrales hydroélectriques, pour obtenir des compensations aux dommages subis par leurs domaines de pêche et pour stopper la prolifération de ces centrales dans la région. Dans ce cas, l'accent est donc essentiellement mis sur l'authenticité, la vigueur et la continuité de la pratique culturelle comme légitimation des luttes politiques avec les autorités brésiliennes.

L'importance accordée à l'authenticité se voit encore dans les réactions des Enawenê-nawê aux accusations d'acculturation. En effet, lorsqu'ils sollicitent certains organismes (Funai, Iphan, municipalité, etc.) pour obtenir des ressources nécessaires au rituel, les Enawenê-nawê doivent parfois affronter des accusations de «perte de culture » (cultura tota, en enawenê), en raison de l'intégration de biens non-traditionnels dans le rite (Nahum-Claudel 2012). Ainsi, en 2009, les Enawenê-nawê durent acheter une grande quantité de poissons auprès d'une ferme piscicole, car la pêche sur leurs barrages n'avait pas été assez fructueuse, en raison de la construction de centrales hydroélectriques en amont. Des employés de la Funai considérèrent ce recours comme l'indice d'une acculturation. Émis par des gens que les Enawenê-nawê tenaient pour leurs alliés dans leur relation à l'État, ces commentaires provoquèrent une vive colère. En 2013, la même incompréhension se reproduisit lorsque la Funai voulut empêcher la construction d'une nouvelle route reliant le village à la ville de Juína, considérant que ce lien avec la société brésilienne risquait de mettre en péril la « culture » indigène : un leader rétorqua que la perpétuation de la « culture » dépendait des maîtres des chants du yaokwa, et nullement des instruments techniques et de la volonté des étrangers. L'authenticité est donc à la fois une exigence et une certitude pour les Enawenê-nawê.

Dans le cas des Suruí, l'exigence de distinction est aussi peu présente que chez les Enawenê-nawê, mais la question de l'authenticité est traitée de manière 
très différente. L'expérience de la recherche de soutiens et de subsides auprès d'administrations publiques, d'ONG indigénistes brésiliennes ou d'organisations étrangères a appris aux Suruí qu'il est crucial de démontrer que leur peuple possède encore sa « culture », mais qu'il convient aussi de souligner que cette maîtrise est fragile, menacée par la pression d'agents extérieurs, incarnés dans la figure tantôt de la " religion » (celle des missionnaires évangélistes), tantôt de la «société de consommation » (à laquelle le trafic de bois permet d'accéder). «Religion » et « société de consommation »sont accusées de fragiliser la culture et de miner l'unité politique et morale du groupe suruí - la première par la division entre croyants et non-croyants et les disputes entre sectes protestantes, la seconde par les inégalités matérielles et jalousies qu'elle entraîne. On pourrait alors croire que la « culture » invoquée serait possédée par l'ensemble du groupe suruí. Cependant, un examen plus attentif aux contextes et enjeux des discours des leaders suruí sur la revitalisation culturelle révèle qu'il s'agit toujours pour une fraction de la population suruí de s'accaparer la démonstration de la « culture suruí » au détriment d'autres. Cet accaparement est tout d'abord un enjeu économique à court terme: dans la mesure où « présenter la culture », c'est organiser un rite de boisson en présence de Blancs dans un village donné, cela permet au participants et résidents de ce village d'en profiter pour leur vendre des biens artisanaux utilisés dans le rituel. À plus long terme, démontrer sa « culture » à des responsables d'une organisation et les faire participer au rite offre l'occasion de tisser des liens privilégiés avec cette organisation (voir Figure 4). Il ne s'agit pas alors de démontrer la spécificité culturelle de cette faction, mais plutôt de souligner son authenticité, en signifiant - parfois très explicitement - aux indigénistes que les factions qui ne participent pas à la performance festive ont succombé aux pressions de la religion ou de la société de consommation, et qu'elles ne seraient donc pas des partenaires fiables pour leurs organisations.

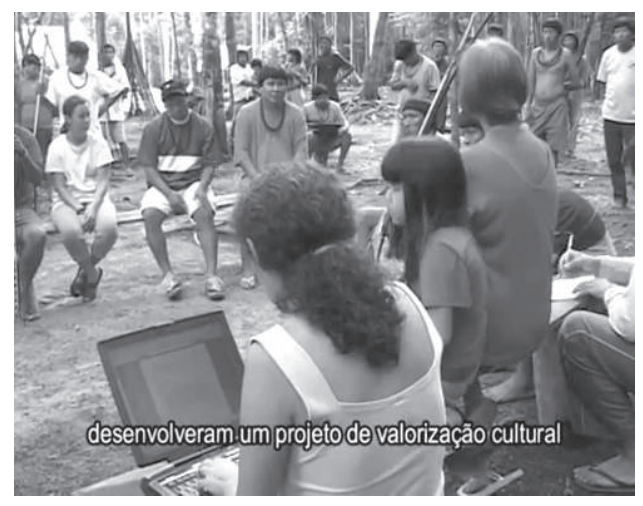

Fig. 4 - Capture d'écran de la vidéo Mapimaí, a festa da criação do mundo segundo o povo Paiter (Alexis Bastos s.d.), mettant en valeur l'implication des membres d'une ONG indigéniste dans l'organisation de la fête filmée.

Enfin, du point de vue des relations internes au groupe et aux diverses factions, l'accomplissement d'un rituel met en jeu les relations entre les générations. En effet, les rites de boisson ont toujours été l'affaire des jeunes hommes - il était rare qu'on y participât encore passé la quarantaine. Leur dynamique naissait des rapports de rivalité entre les jeunes hommes et leurs ascendants ou aînés - le rituel permettait notamment de légitimer des alliances matrimoniales récentes 
qui faisaient l'objet de critiques. Or, en tant que démonstration de la maîtrise de la « culture », la réussite des rites de boisson devient problématique, pour deux raisons. D'une part, il est objectivement évident que les jeunes hommes actuels maîtrisent mal un certain nombre de savoirs et de techniques nécessaires au rituel (confection d'ornements, composition lyrique, etc.). D'autre part, les militants indigénistes qui soutiennent la réalisation du rite attribuent spontanément la maîtrise de la « culture » aux individus les plus âgés, et leur soutien financier est souvent motivé par la crainte de la « perte » de la culture, faute de transmission aux plus jeunes. Les jeunes hommes qui réalisent aujourd'hui des rites de boisson sous le regard des Blancs sont donc pris entre deux exigences contradictoires, nées de la stratégie de l'authenticité menacée: ils doivent à la fois démontrer à leurs aînés qu'ils maîtrisent la «culture » et montrer aux Blancs que cette maîtrise est fragile, ou

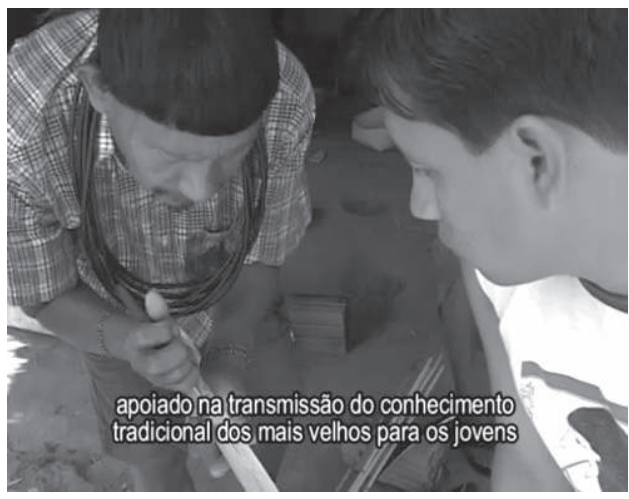

Fig. 5 - Capture d'écran de la vidéo

Mapimaí, a festa da criação do mundo segundo o povo Paiter (Alexis Bastos s.d.). plus exactement conditionnée à la réalisation du rituel, et donc à leur soutien. Aussi les jeunes hommes doivent-ils rechercher l'accord de leurs aînés pour mettre en scène cette transmission de savoir. La mise en spectacle de la « culture » par le rituel s'étend alors à l'exposition « d'enseignements » donnés par des vieux à des jeunes, voire à des enfants, par exemple dans des « ateliers (oficinas) d'artisanat» organisés et financés par les indigénistes avant le rituel: tout comme celui-ci, ces enseignements se font sous l'œil des caméras (voir Figure 5). Cette technique visant à préserver la continuité culturelle est bien sûr tout à fait étrangère aux formes suruí de transmission des savoirs.

Dans ces trois cas, les exigences de distinction et d'authenticité sont donc gérées de manière différente et corrélées à des choix de spectateurs idéaux distincts: en priorité la population régionale, à la fois non-indigène et indigène, chez les Karajá ; l'ensemble de la société brésilienne, et même internationale, chez les Enawenê-nawê; des organisations militantes, ONG écologistes et indigénistes, chez les Suruí. Autrement dit, si chacun de ces groupes, comme bien d'autres en Amazonie, revendique aujourd'hui la possession d'une culture, cette revendication ne s'adresse pas aux mêmes acteurs et partenaires. La culture, c'est-à-dire l'indianité et l'identité ethnique, est donc systématiquement définie de manière relationnelle et contextuelle. Ces enjeux déterminent certaines qualités de la culture telle que se l'attribue chaque groupe: assurée et stable pour les Enawenê-Nawê, dynamique et fragile pour les Karajá et les Suruí. 


\section{Qui choisir pour saisir l'image de sa culture?}

La collaboration entre documentaristes blancs et réalisateurs indigènes est depuis longtemps développée au Brésil, et l'autonomie croissante des groupes amérindiens dans la production d'images d'eux-mêmes est, dans de nombreux cas, considérée comme une avancée importante. Cependant contrôler la production des représentations de sa culture est un enjeu qui peut se poser en termes très différents, voire opposés: il s'agit tantôt d'être capable de reconstruire un regard sur soi, tantôt d'attirer le regard admiratif d'étrangers.

Pour les Karajá, l'acte de se filmer soi-même, caméra au poing (voir Figure 6), constitue en effet le couronnement d'un mouvement de reconquête de leur image, volée et dégradée par les Blancs et les groupes indigènes voisins. Ceux-ci faisaient déjà depuis les années 1980 un usage intense de la vidéo. Après avoir collaboré avec le Museu do Índio dans l'inventaire audiovisuel de leur patrimoine au début des années 2000, les Karajá ont tenu à s'émanciper de leur organisme de tutelle en recherchant un partenaire susceptible de leur offrir en outre une reconnaissance élargie au niveau international. Travaillant déjà avec d'autres groupes du Brésil Central, le MHNT leur offrit à partir de 2010 les moyens techniques d'enregistrement visuel et sonore, comprenant à la fois la fourniture du matériel et la formation à la technique vidéo, dont bénéficièrent essentiellement de jeunes adultes, souvent professeurs dans les écoles de villages. Les Karajá considéraient que pour offrir une image de leur culture qui restât « authentiquement indigène » il était nécessaire

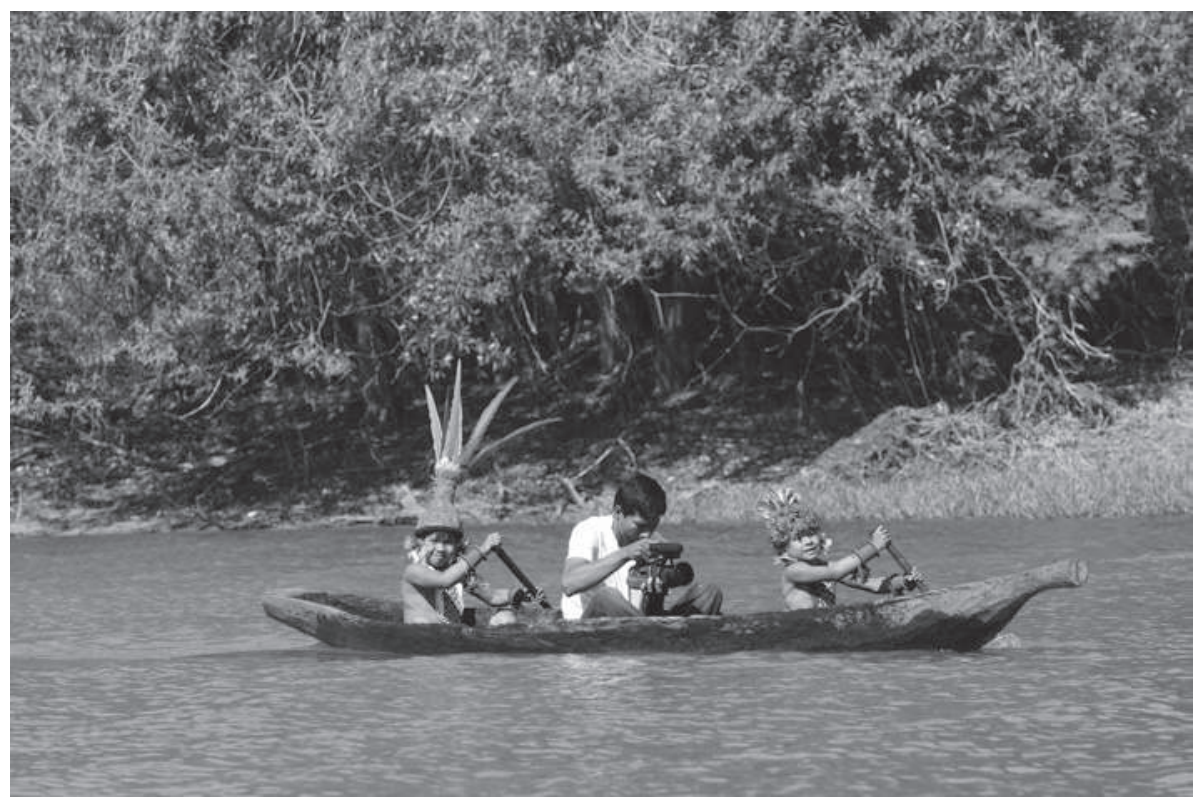

Fig. 6 - Cameraman karajá (photo : Serge Guiraud). 
qu'elle fût produite et contrôlée par eux, et notamment par les individus reconnus comme les plus compétents en matière de culture. De fait, les images tournées par les jeunes gens karajá étaient régulièrement visionnées par les anciens du village. Bien que le montage de ce premier film ait été laissé aux soins du cinéaste professionnel, le choix des rushs a été effectué par les Indiens eux-mêmes, ainsi que la vérification de la version finale. Il est important de préciser ici quel fut le rôle de l'anthropologue dans la réalisation de ce film. Outre sa fonction de médiation entre l'équipe du MHNT et le groupe indigène visant à faciliter la compréhension entre les différents participants au tournage, les Karajá eux-mêmes lui demandèrent d'intervenir à deux niveaux: d'une part, collaborer avec les jeunes vidéastes dans le travail de documentation auprès des anciens que les conduites d'évitement ne permettent pas toujours d'interroger directement; d'autre part, participer au montage du film afin de s'assurer que son contenu soit aussi bien compris par les non-indigènes. En plus du contrôle sur la production de l'image, la technique de la vidéo offre aussi la maîtrise de sa diffusion: les Karajá en ayant la propriété exclusive, le MHNT ne pouvaient diffuser le film sans leur autorisation. Les CD et les DVD sont ainsi devenus des cartes de visite entre les mains des chefs et des professeurs karajá lors de leurs déplacements pour assister à des réunions ou manifestations diverses au Brésil ou à l'étranger. Dans ce contexte interethnique de compétition identitaire et après des années d'exploitation iconique par les Blancs, la conquête de la production et de la diffusion de l'image de sa culture constitue un élément déterminant du mouvement de patrimonialisation.

Au contraire, dans le cas des Enawenê-nawê et des Suruí, la production de vidéo est réalisée principalement par des étrangers, à l'initiative d'organisations indigénistes. Chez les premiers, après des œuvres d'ONG, en particulier des productions de Vídeo nas Aldeias (Valadão 1995), dont une a été tournée en vue de l'inscription patrimoniale du yaokwa par la même organisation (Carelli et Campoli 2009), des chaînes de télévision sont venues, étrangères - ZED/ Arte/Discovery (Léonardelli 2005) - puis brésilienne - Globo (Francisco 2012). Les réalisateurs se sont adressés aux Enawenê-nawê parce qu'ils répondaient à la contrainte inhérente à la vidéo d'envisager la culture comme un spectacle. À ce jour, chez les Suruí, la mise en spectacle vidéo du rituel n'a pas dépassé le stade de productions d'organisations indigénistes (dont la plus active est l'Associação Kanindé de Defesa Etno-Ambiental), sous forme de vidéocassettes puis de DVD (Bastos s.d.). Dans les années 1990 et 2000, ces organisations payaient des caméramans professionnels et se chargeaient ensuite du montage, sans intervention des Indiens. Depuis la fin des années 2000, le tournage peut être assuré par de jeunes hommes Suruí, en tant qu'employés d'une association clanique ou d'une ONG indigéniste. ${ }^{11}$ Dans les deux cas, aujourd'hui, en sus de

11. Quelques jeunes Suruí ont reçu des formations aux techniques de filmage et de montage dans le cadre de projets mis en œuvre par des organisations indigénistes. 
cet enregistrement « officiel », les nombreux possesseurs de smartphones ou de caméscopes filment le rituel et ces vidéos - souvent très brèves - sont regardées dans le cercle familial ou parfois, chez les Suruí, publiées sur internet et montrées à des visiteurs étrangers. Or, si l'accès aux moyens de production vidéo est très apprécié - comme insigne de richesse et de modernité - cet élargissement des moyens d'enregistrements n'a pas (encore?) vraiment remis en cause le contrôle que le regard extérieur, incarné par la caméra professionnelle, exerce sur la patrimonialisation du rituel. Chez les Enawenê-nawê, toute image saisissant la beauté du rituel est certes intrinsèquement appréciée. Cependant l'existence d'un regard extérieur porté sur leur rituel reste un facteur important, qui vient satisfaire un désir de « reconnaissance existentielle », telle que l'analyse Laura Graham (2012) dans certaines communautés xavante. L'éloignement même de l'observateur vient attester de leur authenticité insurpassable. Chez les Suruí, ce regard extérieur est encore plus crucial, puisqu'il conditionne quasiment la réalisation même du rituel, de manière très explicite: " Aujourd'hui, nous ne faisons plus de fêtes que s'il y a une télévision [un caméraman professionnel] qui vient au village », affirma ainsi en 2005 un homme, qui n'était en rien impliqué dans le tournage vidéo. Or dix ans plus tard, tous les rituels qui ont eu lieu ont été filmés par des caméramans rétribués par des indigénistes.

Ni la continuité de la pratique patrimonialisée - jamais interrompue chez les Enawenê-nawê, redevenue régulière chez les Karajá après un déclin dans les années 1980, très intermittente chez les Suruí depuis les années 1990 -, ni la valorisation de la vidéo - forte dans tous les cas -, ni même le désir de s'approprier des moyens technologiques modernes - intrinsèquement désirables - ne peuvent donc expliquer l'attitude relative au contrôle de la production d'images de soi. C'est bien plutôt le rôle attribué au regard extérieur qui est en jeu ici. Dans un cas, celui des Karajá, il s'agit, pour affirmer la puissance et l'autonomie de sa culture, de prouver sa capacité à construire soi-même le regard qui sera porté sur elle. Dans les autres, il s'agit de prouver sa beauté par le désir des étrangers de la contempler. Ces attitudes font donc écho à l'équilibre trouvé dans chaque société entre les exigences d'identité et d'authenticité. Elles ne se réduisent cependant pas à la seule question du maniement de la caméra afin de produire une image destinée à des téléspectateurs génériques. En effet, l'observation de la production des vidéos montre que la notion de spectateur de la culture est bien plus complexe.

\section{Que faire des spectateurs du patrimoine culturel?}

Le fait que ces démonstrations de culture s'opèrent au moyen d'un spectacle qui est un rituel pose en effet un problème spécifique. Ces rituels définissent tous une (ou parfois plusieurs) place de spectateur. Chez les Enawenê-nawê, la position de spectateur est déjà inscrite au cœur même du rituel yaokwa. 
Celui-ci repose sur une dynamique d'échange dans lequel, lors d'un cycle donné, un clan fournit du bois de chauffe, de la nourriture et des boissons aux huit autres clans, qui boivent, dansent et chantent, incarnant ainsi les esprits du clan donateur; les membres de ce dernier, ainsi que toutes les femmes du village, observent et écoutent alors le spectacle des hommes jouant des flûtes sur la place centrale. Chez les Karajá aussi, la relation dyadique et spéculaire entre le soi et l'autre, qu'il soit collectif ou individuel, proche ou éloigné, impose sa règle dans l'espace cérémoniel. Ainsi, le heto hokã est structuré par l'opposition amont/aval des groupes en présence. La vidéo ne fait donc que redoubler cette « technologie relationnelle » du rituel permettant de se voir dans le miroir tendu par l'autre. Chez les Suruí encore, le rituel de boisson offrait aussi déjà la possibilité d'une auto-contemplation: le producteur de bière écoutait les chants des buveurs qui célébraient son action ${ }^{12}$. Quelles relations s'établissent alors entre cette position de spectateur indigène, inclus dans le schéma relationnel du rituel, et celle de spectateur étranger, destinataire des productions vidéo, ou participant à ce tournage?

De ce point de vue les Enawenê-nawê représentent un cas où ces deux positions restent strictement séparées. Jusqu'à présent, les Enawenê-nawê n'ont jamais convié aucun étranger, proche ou lointain, à observer le yaokwa ou à y prendre part - à l'exception des équipes de tournage (voir Figure 7). Les spectateurs étrangers supposés visionner les vidéos n'assistent aucunement au rituel « réel» et y participent encore moins. Les futurs téléspectateurs des vidéos produites sont donc conçus comme lointains, désincarnés et abstraits. Étant donné les énormes ressources qu'il requiert, en nourriture, en outils ou en carburant, l'accomplissement du yaokwa nécessite certes souvent de solliciter le soutien de partenaires non-indigènes - et ce phénomène s'était développé avant que le rituel ne fût patrimonialisé et filmé. Ces partenaires sont encore considérés comme des entités officielles et des personnes morales: les Enawenê-nawê disent toujours s'adresser à « la Funai », à « la municipalité », à « l'Iphan », à « la compagnie hydroélectrique » et même à « l'OPAN », plutôt qu'aux dirigeants ou représentants de ces entités, pourtant bien connus des Indiens. Même si le fonctionnement de la bureaucratie brésilienne laisse une place notoire aux relations de patronage et de réciprocité personnelle, dans le cadre de la réalisation du rituel, les Enawenê-nawê se considèrent comme un collectif envers qui ces autres collectifs auraient des obligations en raison de l'importance du yaokwa pour l'ordre cosmologique. Strictement séparés spatialement, les

12. Dans les trois cas, visionner les images des rituels du groupe, ainsi que parfois de ceux d'autres groupes amazoniens, constitue une distraction appréciée. Les premiers spectateurs et amateurs de ce type d'œuvre sont souvent les indigènes eux-mêmes, et chacun y va de ses commentaires, comparaisons ou critiques sur la performance des participants au rituel. Cette évaluation de la performance pouvant être un des principaux mobiles individuels de la participation au rituel, notamment chez les Suruí, l'enregistrement vidéo incite fortement à y prendre part. 
Pourquoi filmer sa culture?

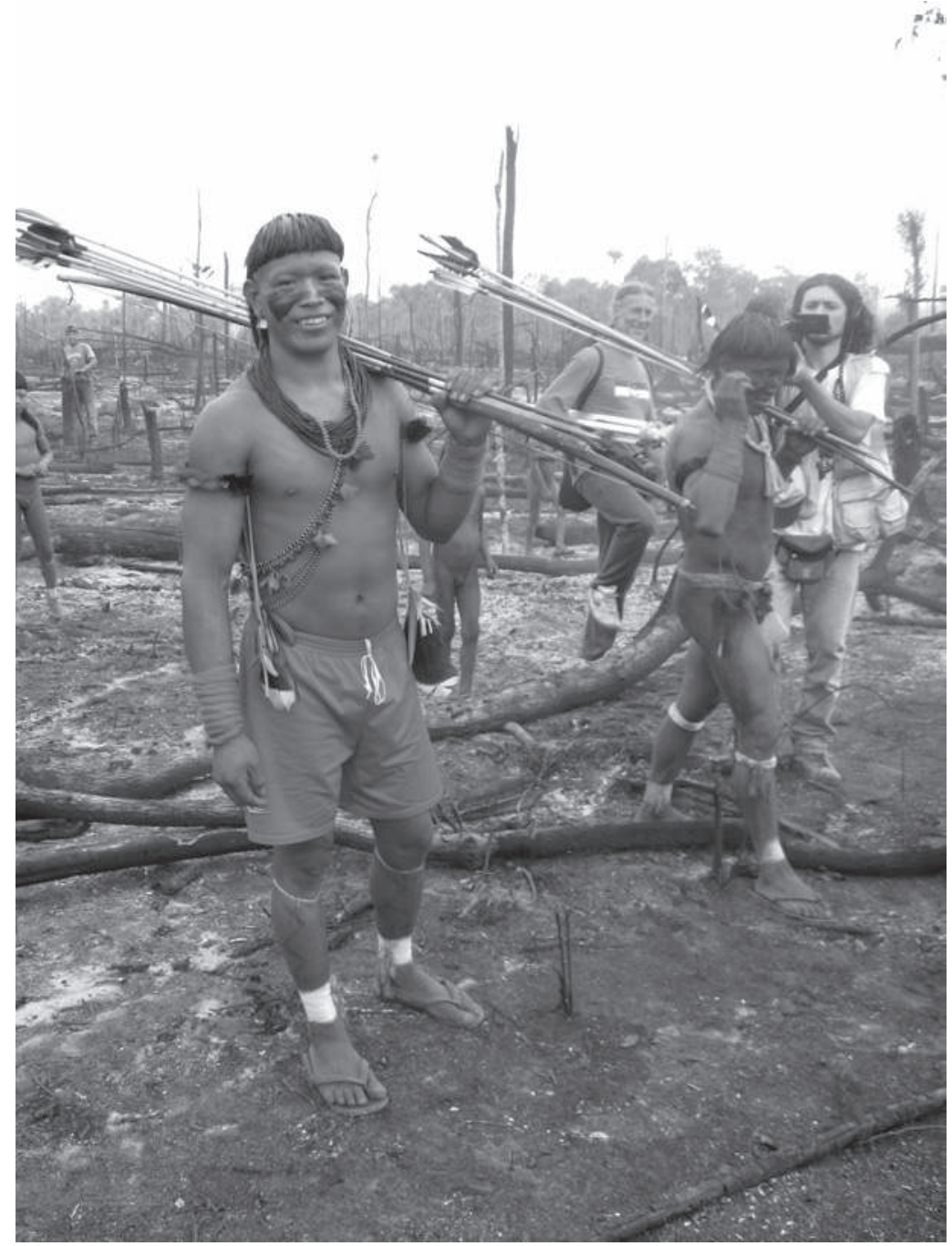

Fig. 7 - Tournage d'une vidéo chez les Enawenênawê (photo: Chloé Nahum-Claudel).

acteurs et spectateurs indigènes et étrangers sont donc supposés partager un même intérêt commun, de nature esthétique et existentielle, dans la réalisation et la contemplation du rituel.

Au contraire, chez les Karajá et les Suruí, les spectateurs étrangers sont indéniablement intégrés dans le rituel patrimonialisé. Chez les premiers, la tenue du rituel d'initiation masculine, précédé et suivi par des danses de masques sur plusieurs semaines, nécessite une forte mobilisation collective en termes de 
ressources alimentaires, d'assistance chamanique, de confection et d'interprétation des entités masquées. Les maîtres du rituel ou parents des jeunes initiés doivent pouvoir activer, en fonction de la phase cérémonielle, un réseau de relations sociales important, qui va de la parentèle corésidente à celle élargie aux membres des villages invités. Suivant un codage précis, ces services sont rétribués, au cours ou à la fin de la cérémonie, par de la nourriture cuite, des objets rituels ou des ornements corporels. Or aujourd'hui, la réalisation du heto hokã peut difficilement se passer de la participation des Blancs, car la nourriture servie durant le rituel est en grande partie achetée dans les bourgs brésiliens les plus proches. Ainsi, les non-indigènes intègrent et élargissent ce réseau d'échanges cérémoniels : en échange d'un spectacle indigène avec autorisation de photographier ou de filmer, ils sont priés de verser une contribution, tantôt en argent - dans le cas des élus, des représentants d'ONG, des musées ou d'autres institutions - tantôt en alimentation - dans le cas des particuliers ou des commerçants locaux. Mise en scène esthétisante et « culturellement authentique », le heto hokã sert également de vitrine commerciale pour la production artisanale des Karajá. Utilisés ou non lors du rituel, de nombreux objets et ornements corporels sont fabriqués dans la phase préparatoire afin d'être vendus aux Blancs; même les membres des autres villages venus participer à la cérémonie arrivent chargés de pièces artisanales destinées à la vente. Plus les maîtres du rite d'initiation masculine pourront attirer de spectateurs non-indigènes, plus nombreux seront donc les Karajá à bénéficier de cette manne financière. Explicite, organisée et quantifiée, cette participation des non-indigènes au rituel karajá les laisse cependant dans une position marginale. Les Blancs contribuent financièrement à la mise en scène et peuvent la contempler, voire participer à certains jeux rituels, mais ils sont cantonnés dans l'observation d'une partie du rite, sans accéder à ce qui est interdit aux non-initiés.

De ce point de vue, l'intégration des spectateurs étrangers est peut-être plus poussée dans la mise en œuvre du rituel suruí. Les rites de boisson impliquaient toujours une position de spectateur, revenant aux individus qui se trouvaient exclus du rituel parce qu'ils n'avaient pas été sollicités par l'un ou l'autre des leaders, comme producteurs ou comme consommateurs de bière: des gens trop vieux, trop jeunes ou trop pauvres pour participer aux fêtes. Ces observateurs passifs jouaient de fait un rôle important dans le rituel : par leur regard et leurs commentaires, ils étaient un facteur clé de la « renommée » des participants. Aujourd'hui plusieurs Blancs, outre les caméramans et leurs assistants, sont souvent présents sur les lieux du rituel: un ou deux employés de la Funai, au moins quatre ou cinq indigénistes brésiliens ou étrangers, parfois un politicien local et plus rarement quelques colons voisins; il arrive aussi que des leaders indiens d'ethnies lointaines soient présents (voir Figure 8). Ces étrangers qui observent la consommation de bière, les danses et les chants viennent donc aujourd'hui occuper une place qui a toujours existé et jouent un rôle tout à fait similaire, lorsqu'ils filment une fête. 


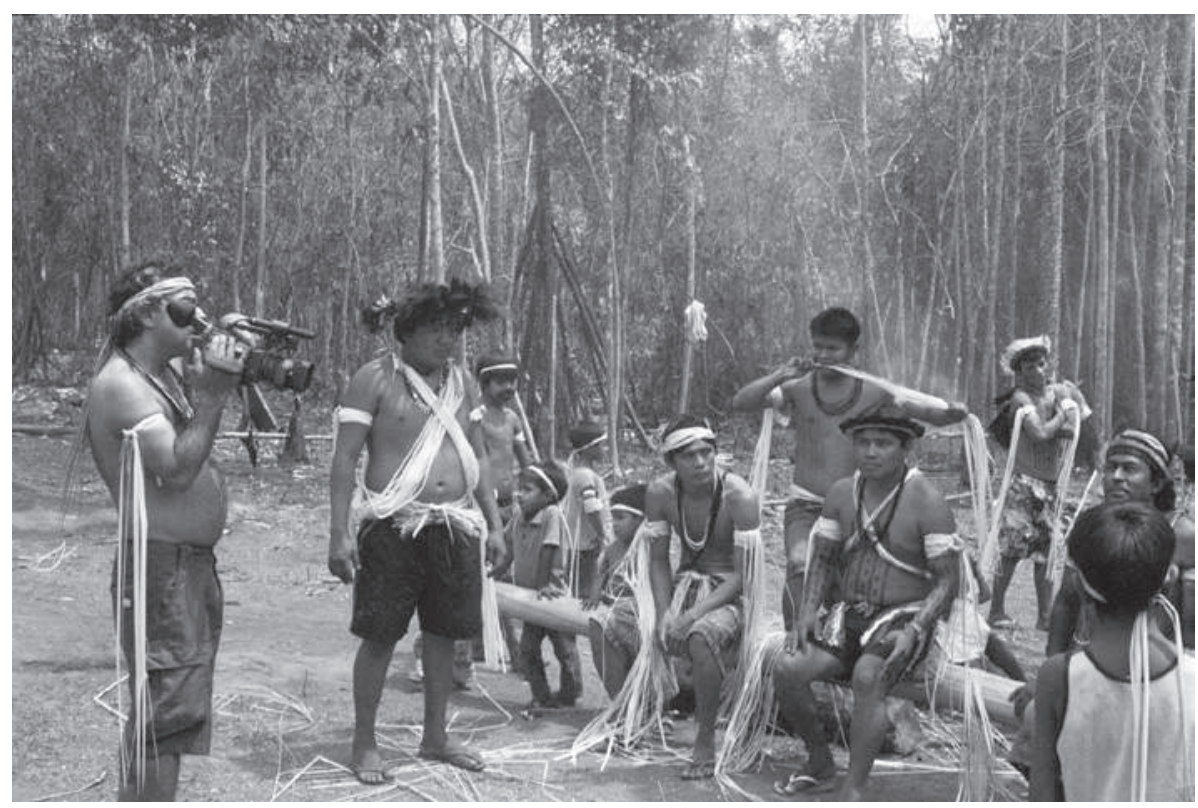

Fig. 8 - Cameraman professionnel interviewant le grand leader indigène Ailton Krenak (à droite), invité à une fête de boisson suruí (photo: Cédric Yvinec).

Toutefois, ils ne sont pas seulement des spectateurs passifs et de simples véhicules de la « renommée ». En tant que promoteurs du rituel et partenaires d'échange de biens ayant lieu à l'occasion du rituel, ils en sont des participants actifs. En effet, le rite de boisson devient un élément d'un système d'échange de biens matériels et symboliques. Les Suruí tentent systématiquement de vendre les ornements corporels (colliers, diadèmes) et les flèches qu'ils utilisent à l'occasion du rite. Certains ont conscience du fait que la valeur de ces objets pour les invités étrangers vient de leur origine indienne et qu'elle est renforcée par l'observation directe de leur manipulation dans le rituel comme le montre l'invention de diverses théories sur les propriétés symboliques ou magiques de ces biens (« insigne de chef », « effet purificateur », etc.) pour leurs acheteurs potentiels. Dans le rite sous sa forme traditionnelle aussi, ces biens étaient cédés par les consommateurs aux producteurs, " en échange » (wepi) de la bière et le fait d'avoir été obtenus dans ce cadre d'échange rituel conférait à ces biens leur prestige. «En échange » (« vendre » est traduit par le même terme, wepi) de ces biens, ainsi que du spectacle festif dans son ensemble, les étrangers fournissent, non certes de la bière, mais de l'argent. Dans un cas comme dans l'autre, il s'agit là d'un bien alimentaire par excellence: la bière de maïs était autrefois la « vraie nourriture des gens renommés », par opposition au manioc ou aux produits de la cueillette; l'argent est ce qui permet aujourd'hui de nourrir 
dignement sa famille et ses hôtes à base de produits achetés (riz, haricots et viande congelée), par opposition aux produits de l'essart sur lesquels on se rabat lorsqu'on est dans le dénuement. En outre, les fêtes de bière fermentée sont parfois suivies de beuveries de boissons alcoolisées commerciales, achetées en partie grâce à l'argent ainsi gagné, et réunissant producteurs et consommateurs de bière fermentée dans une ivresse commune. De ce fait, le nouveau système d'échange rituel produit un échange comparable: des produits alimentaires et enivrants contre des objets ornementaux, esthétiques, valorisés par leur origine étrangère et par le regard d'autrui.

Il arrive d'ailleurs que les Suruí proposent aux visiteurs étrangers de prendre part brièvement aux activités rituelles. Ils sont alors toujours intégrés en position de consommateurs, en participant à une danse collective ou en goûtant une coupe de bière - qu'ils seraient certes bien en peine de produire. Dans un rituel traditionnel, accepter de consommer la bière d'un producteur, c'était à la fois s'exposer au risque de « mourir » symboliquement, en s'effondrant sous l'effet de l'ivresse, et s'engager implicitement à rendre l'invitation. Les Blancs ne boivent certes pas assez pour perdre conscience, les Suruí ne s'attendent pas à être conviés par eux à une fête de boisson. En les faisant participer activement au rituel, les Suruí cherchent néanmoins à engager une dynamique relationnelle avec eux, s'appuyant explicitement sur la mémoire de cette expérience - « Maintenant, tu n'as plus le droit de nous oublier! »

L'intégration des spectateurs au processus cérémoniel témoigne chez les Suruí d'une confiance dans l'efficacité du rituel comme instrument relationnel, et fait écho à leur absence d'angoisse quant à son éventuelle inauthenticité. Au contraire chez les Karajá, la préservation de l'authenticité du rituel restreint l'intégration des spectateurs étrangers par leur affectation dans la catégorie des non-initiés auxquels l'accès au sacré reste formellement prohibé.

\section{Étaler sa culture, c'est aussi la cacher}

La mise en spectacle visuel de «cultures » indigènes des Amériques et d'Océanie a donné lieu à des débats récurrents depuis une trentaine d'années (MacDougall 1987; Ginsburg 1991; Turner 1992; Weiner 1997; Myers 2014), principalement dans des contextes australiens et mélanésiens. L'une des critiques les plus vives a été formulée par J. Weiner, qui affirmait que les représentations visuelles étaient incapables de saisir ce qui aurait formé le cœur des « cultures » considérées - des savoirs dont la valeur viendrait de leur caractère ésotérique - et qu'en conséquence l'appropriation des techniques vidéo par les populations indigènes mettait en danger cette culture « authentique ». Or non seulement une telle critique fait bon marché des valeurs très variables que les conceptions indigènes attribuent à «l'authenticité », et oublie d'explorer les dynamiques créatives qui naissent de l'interaction entre les savoirs indigènes 
et les technologies étrangères, comme nous avons essayé de le faire ici, mais surtout, elle manque le fait que c'est précisément parce qu'elles sont incapables de saisir certaines dimensions de leur culture, que certains groupes indigènes apprécient les représentations visuelles.

Dans le cas des Karajá et des Enawenê-nawê, les rituels dans lesquels s'incarne la « culture » ont toujours comporté une part ésotérique. Depuis qu'il est utilisé à des fins patrimoniales, le rituel karajá reconduit la même distinction entre ce qui pouvait être donné à voir et ce qui devait être caché dans sa forme traditionnelle. En effet, les étrangers ne sont pas autorisés à photographier ou à filmer, ni même à voir ce qui traditionnellement est occulté au regard, voire à la connaissance, des femmes, des enfants et des jeunes garçons non-initiés; tous ces aspects restent donc exclus du processus de mise en patrimoine. C'est le cas en particulier de l'intérieur de la maison des hommes, réservé aux initiés: les visiteurs non-indigènes n'ont pas le droit de voir, ni de filmer ce lieu de transmission du savoir ésotérique, de fabrication et de conservation des masques, donc de résidence des entités spirituelles durant le rituel, et dont l'accès est strictement réservé aux hommes sous peine de sanction. L'interdit visuel porte également sur aõni hokã (« grand monstre »), l'entité cannibale qui sort nuitamment de la maison des hommes et dont la connaissance et la manipulation relèvent de la responsabilité exclusive d'une petite minorité d'hommes karajá. Le rôle du masque chez les Karajá illustre parfaitement cette distinction instituée entre le visible et le non-visible dans la mise en spectacle de la culture, dans cette construction patrimoniale qui opère une sélection dans le corpus culturel. Incarnant des entités spirituelles, humaines ou animales, les masques, au même titre que les trophées de guerre ou les instruments de musique, sont des objets symboliques qui par définition rendent visibles des relations avec l'invisible. Le pouvoir qu'ils incarnent ne peut être maîtrisé et utilisé que par des initiés. Néanmoins, leur aspect mystérieux et leur beauté étrange leur confèrent une valeur culturelle importante vis-à-vis de l'extérieur. Chez les Karajá, le masque est ainsi l'objet médiatique par excellence, l'emblème culturel que l'on met en avant et que l'on donne à voir - une fois sorti de la maison des hommes - parfois même sur simple demande d'un visiteur. Pour autant, la charge spirituelle qui lui est associée et la relation étroite de paternité liant le maître du rituel à l'entité masquée, interdisent toute réutilisation de l'enveloppe matérielle ayant servi à incarner l'esprit. À la fin du rituel, les masques karajá sont soit enterrés, soit brûlés, en fonction de l'esprit qu'ils ont incarné (Pétesch 2011). En conséquence, à la différence des groupes voisins du Haut-Xingu qui acceptent sous certaines conditions de commercialiser leurs masques (Barcelos Neto 2006), les Karajá refusent de vendre les leurs, que ce soit à des particuliers ou des musées en vue d'intégrer des collections. Le masque semble exprimer ainsi la distinction qui s'opère dans la pensée karajá entre, d'une part, ce que le non-indien est capable de voir ou est autorisé à voir, à savoir une extériorité corporelle, un 
simple « objet rituel » exotique et attractif, et, d'autre part, ce qui relève d'une intériorité immatérielle, invisible au non-initié ou délibérément occultée. Ici le regard extérieur qu'implique la patrimonialisation est donc accepté dans la mesure où il se soumet aux restrictions traditionnelles et où les spectateurs étrangers adoptent la position de non-initiés.

Dans le cas des Enawenê-nawê, l'importance accordée au spectacle par les équipes de tournage s'accorde très bien à l'épistémologie enawenê-nawê, car elle permet d'éviter d'expliciter le savoir ancestral détenu par des spécialistes (sotakatale, « savants », devenus tels par apprentissage contre paiement auprès d'un ou plusieurs prédécesseurs), en mettant en avant les aspects esthétiques et théâtraux: la performance chorégraphique, les mises en scène d'épisodes mythologiques, les artefacts, l'ornementation et les longues séquences d'action comme la construction d'un barrage de pêche. Le montage du film Yaokwa, um patrimônio ameaçado, réalisé par Vídeo nas Aldeias pour l'Iphan, cherche à créer des scènes qui forment des unités de signification sans nécessiter de commentaire hors-champ, conformément au partis-pris esthétique et politique de cette ONG (Caixeta de Queiroz 2004). On entend fonder la compréhension du spectateur sur l'image et l'action seules. La cohérence du film s'appuie seulement, de temps à autre, sur l'insertion d'une courte interview d'un Enawenênawê fournissant des explications ponctuelles à l'équipe de tournage. Or ces explicitations indigènes reconduisent la même primauté de la vision. Comme à leur habitude, les Enawenê-nawê s'appuient alors sur des petites interprétations, au sens théâtral, dans lesquelles un épisode mythique ou une interaction rituelle sont joués afin de les expliquer. En revanche, certaines interactions verbales de première importance sont coupées au montage ou extrêmement réduites : la récitation du chamane visant à assurer la fertilité de la « mère du manioc » qui peut durer jusqu'à cinq heures est montrée en quelques secondes, sans la moindre traduction des paroles. De nombreuses scènes de danses et de chants sont présentées, toujours sans aucune indication sur le contenu des chants ni, plus largement, sur le sens et la raison de ces danses. La vidéo peut bien saisir tout ce qui est, par nature, visible, public et partagé; le vrai savoir, c'est-à-dire les chants, les noms secrets et les récits chamaniques, ne sera pas exposé, de telle sorte que le cœur métaphysique du yaokwa reste un mystère pour le spectateur du film. Or tous les aspects du rituel qui peuvent apparaître comme théâtraux, esthétiques, matériels ou économiques, sont mis en avant. Cependant pour les Enawenê-nawê ces aspects n'ont de sens qu'en lien avec les chants, les récits et les dialogues cérémoniels qui les accompagnent. Le film garde donc le silence sur le lieu véritable du savoir pour ses acteurs. Le choix d'une patrimonialisation filmique reflète certes la priorité accordée à la dimension visuelle par les intermédiaires de la production de « culture indienne authentique ». Mais ce choix aussi semble satisfaire pleinement les Enawenênawê, précisément parce qu'il permet de laisser dans l'ombre les savoirs qui 
restent réservés à une transmission entre spécialiste et novice. Malgré le but officiel de sauvegarde culturelle qui, selon les Enawenê-nawê dépend avant tout de l'apprentissage par les jeunes du corpus de chants, théorie reproduite dans le dossier d'inventaire de l'Iphan, ce corpus n'est y jamais documenté de manière effective. Aussi, dans ce cas, contrairement à d'autres (voir de Vienne et Allard 2005 et Fausto 2016) la patrimonialisation reste-t-elle nettement dissociée de la transmission de la culture valorisée au sein du groupe.

Chez les Suruí en revanche, les rites de boisson n'étaient nullement associés à un savoir ésotérique - bien au contraire, ils faisaient partie du " savoir » (kobamne) au sens simple, c'est-à-dire ouvert à tous et commun à tous les champs d'activité, par opposition au « savoir du cœur » (agõa-kobamne), propre aux chamanes, inexplicable et impartageable. En outre, s'il existait bien un symbolisme associé à divers actes rituels, celui-ci était plutôt pauvre, peu systématique, assez déconnecté d'autres champs (mythologie, chamanisme) et peu explicité dans des discours réflexifs. Or la patrimonialisation du rituel a donné lieu à la création d'un discours réflexif sur celui-ci, discours qui est manifestement produit pour répondre à des attentes supposées des Blancs et qui témoigne parfois de la maîtrise de notions anthropologiques vulgarisées. En effet pour les interprètes suruí qui s'occupent des visiteurs étrangers lors d'un rituel (voir Figure 9), il paraît important de fournir un discours explicatif

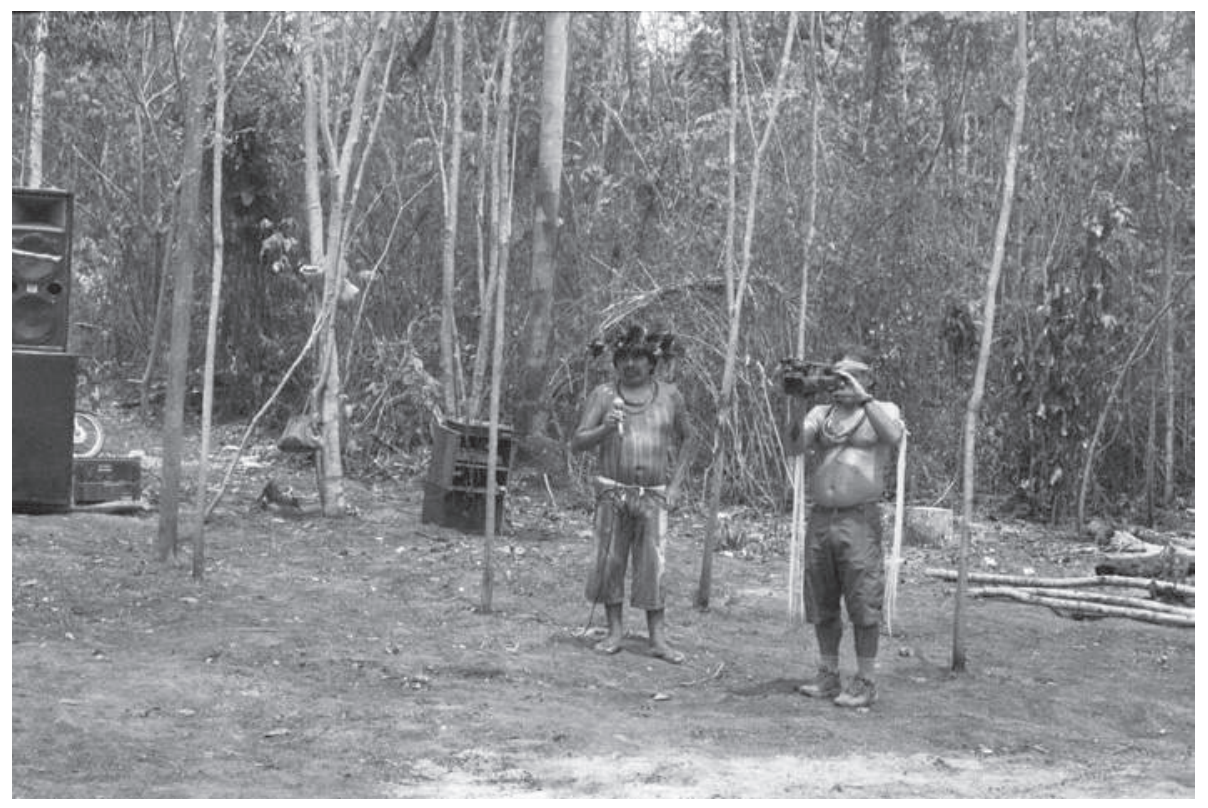

Fig. 9 - Leader suruí commentant et expliquant le sens de la fête durant le tournage (photo: Cédric Yvinec). 
renvoyant à un savoir que les auditeurs peuvent concevoir comme vaguement ésotérique. Ainsi, les vomissements qu'entraînent la consommation de la bière sont qualifiés de « purificateurs »; la dimension agonistique inhérente à la relation entre producteurs et buveurs est décrite comme un match sportif avec un perdant et un gagnant (le buveur s'il réussit à tout boire); le rituel est qualifié de " fête de la création du monde », célébrant « une époque où les animaux étaient humains », par référence à un mythe où des personnages humains acquièrent les propriétés spécifiques de leurs éponymes animaux dans le contexte d'un rite de boisson. Ces commentaires obligeamment fournis aux Blancs sont des discours produits exclusivement en portugais ; lorsqu' on le leur demande, leurs auteurs sont souvent incapables d'en retraduire en suruí les concepts-clés (tels que « perdre » et « gagner une fête »). Une vidéo produite par l'Associação Kanindé, diffusée sous forme de DVD puis sur Youtube (Bastos s.d.) présente d'ailleurs de multiples exégèses contradictoires de l'activité rituelle: des interviews en suruí ou en portugais des participants aux réponses purement factuelles ( «j'apprends aux jeunes à confectionner des ornements », « je vais boire »), une narration en suruí qui insiste sur la dimension politique de l'événement (« nous [= notre faction] sommes capables d'agir comme des grands hommes ») et un sous-titrage en portugais, traduit par le même narrateur, qui s'écarte souvent des discours en suruí pour insister sur le symbolisme de la fête (« le feu représente l'indépendance humaine au temps de la création du monde »).

Alors que ce supposé symbolisme rituel est diligemment exposé aux visiteurs, parfois par un traducteur officiellement désigné et rétribué, la dynamique même du rituel, reposant sur la rivalité entre paires de factions festives liées par l'échange de bière et de biens artisanaux n'est jamais évoquée. La seule rivalité évoquée pour les Blancs est celle entre producteurs et consommateurs de bière, mais elle est, à juste titre, décrite comme ritualisée et contrôlée. En revanche, elle est présentée comme englobant l'ensemble de la population suruí, dans une sorte de système à moitiés, et elle est ainsi supposée « rassembler le peuple » pour « renforcer son unité », ce qui est hautement discutable, tant du point de vue de la logique traditionnelle des fêtes que de celui de la dynamique actuelle de démonstration de la « culture », dans laquelle une paire de factions festives cherche à accaparer les relations avec telle ou telle organisation indigéniste à son profit. Les dimensions réellement conflictuelles du rituel sont ainsi passées sous silence. Ce sont donc aussi les tensions qui motivent la patrimonialisation et la dynamique profonde de la culture qui sont occultées par cette profusion nouvelle de symbolisme dans le rituel suruí.

\section{Conclusion}

Dans cette comparaison entre trois processus, les Karajá apparaissent comme un groupe qui parvient à intégrer des spectateurs étrangers à l'incarnation rituelle de sa « culture » en leur imposant de se conformer à des distinctions traditionnelles 
- initiés vs non-initiés - dans une situation où la définition de la «culture » a pourtant fait l'objet d'une détermination extérieure contribuant fortement à la construction du parcours patrimonial. À l'inverse, les Suruí n'ont guère eu à se confronter à d'autres groupes indigènes ou étrangers dans la définition de leur « culture », qui obéit toujours à une logique interne; mais s'ils réussissent à intégrer les spectateurs étrangers à leur rituel, ce dernier est profondément affecté dans son déroulement et surtout dans les discours réflexifs qui sont énoncés à son sujet et qui commencent à dominer l'interprétation de cette pratique chez les jeunes générations. Quant aux Enawenê-nawê, ils ont réussi à tenir les spectateurs de leur culture à distance. Ces trois rituels réagissent donc différemment aux contraintes et opportunités offertes par la demande de culture indigène par différents acteurs étrangers, institutionnels ou non. Ainsi, les objets patrimonialisés rendent possibles, imposent ou interdisent certains types d'interaction avec les étrangers au regard desquels ils sont offerts; et c'est ici que se joue le destin de la « culture » et sa résistance aux effets de la patrimonialisation.

Notre analyse comparée de ces trois cas d'usage d'une même technique, la vidéo, pour documenter des pratiques visuellement assez similaires, afin de répondre à une même exigence d'exhibition culturelle, fait donc apparaître le processus de patrimonialisation comme une appropriation de la «culture» de certains groupes sociaux - des Blancs, des membres d'ONG, des producteurs télévisuels, etc. - par les Indiens, au sens plein: à la fois sur le plan intellectuel, par la réinterprétation de la notion de culture, sur le plan technique, par l'accès à la production d'images de soi et sur le plan social, par l'usage de ces instruments matériels et symboliques dans la reconfiguration de différentes relations politiques, internes et externes au groupe. Dans certains contextes, comme celui du Haut-Xingu où les échanges de rituels entre groupes sont une pratique installée depuis plusieurs siècles, la mise en spectacle de rituels a pu être envisagée comme une continuation de cette pratique de la cession de savoirs rituels en échange d'une acceptation dans un système d'alliance inter-ethnique (Fausto 2011). Les groupes ici considérés ne pratiquaient rien de tel, ou n'envisageaient ces échanges de rituels que sous l'angle de l'appropriation de rituels étrangers. Or c'est finalement bien ce qui se produit à travers le processus de patrimonialisation: des notions et des pratiques étrangères sont intégrées dans des rites et en reconfigurent les enjeux. La patrimonialisation n'est donc pas uniquement une cession de savoirs et une soumission à des notions étrangères, mais aussi une acquisition et une intégration dans des enjeux locaux. En ce sens, l'attitude de ces groupes amazoniens face aux organisations qui leur proposent d'exposer leur culture en vidéo constitue sans doute une continuation de la digestion de l'altérité à travers l'appropriation d'éléments de rituels étrangers, dynamique qui animait ces sociétés bien avant leur rencontre avec les caméras et les registres des institutions nationales et internationales. *

* Manuscrit reçu en février 2016, accepté pour publication en avril 2017. 


\section{Références citées}

Barcelos Neto Aristóteles

2006 «Des villages indigènes aux musées d'anthropologie. De la propriété et la vente des objets rituels amazoniens ", Gradhiva, 4, p. 87-95.

Bastos Alexis

s.d. Mapimaí. A festa da criação do mundo segundo o Povo Paiter [vidéo], Rioterra/ Kanindé/Paiterey, $38 \mathrm{~min}$, https://www.youtube.com/watch?v=1AVwxfkV9M, consulté le 20 octobre 2017.

BESSIRE Lucas

2014 «The rise of Indigenous hypermarginality: native culture as a Neoliberal politic of life », Current Anthropology, 55 (3), p. 276-295.

BOYER Dominic

2006 « Turner's anthropology of media and its legacies », Critique of Anthropology, 26 (1), p. 47-60.

Caixeta de Queiroz Ruben

2004 «Política, estética e ética no projeto Vídeo nas aldeias », in Mari Corrêa, Sérgio Bloch, Vincent Carelli (coord.), Mostra Video nas aldeias: um olhar Indigena/ Video in the villages exhibition: through Indian eyes, catalogue de l'exposition «Vídeo nas Aldeias. Um Olhar Indígena » [20-25 avril 2004], http://www. videonasaldeias.org.br/2009/biblioteca.php?c=20, consulté le 23/10/17.

CAÑAS Vicente

s.d. « Diario de campo 1980-1987 », archives de l'Operação Amazônia Nativa (OPAN), Cuiabá.

Carelli Vincent et Fausto Campoli

2009 Yaõkwá, um patrimônio ameaçado [vidéo], Vídeo nas Aldeias, 54 min.

CARneiro dA Cunha Manuela

2010 Savoir traditionnel, droits intellectuels et dialectique de la culture, Éditions de l'Éclat, Villefranche-de-Rouergue.

Conklin Beth A.

1997 «Body paint, feathers, and VCRs. Aesthetics and authenticity in Amazonian activism », American Ethnologist, 24 (4), p. 711-737.

2002 "Shamans versus Pirates in the Amazonian treasure chest », American Anthropologist, 104 (4), p. 1050-1061.

De VIEnNe Emmanuel et Olivier Allard

2005 «Pour une poignée de dollars? Transmission et patrimonialisation de la culture chez les Trumai du Brésil central », Cahiers des Amériques latines, 48-49, p. 126-145.

Fausto Carlos

2011 «Mil años de transformación. La cultura de la tradición entre los Kuikuru del Alto Xingu », in Jean-Pierre Chaumeil, Óscar Espinosa de Rivero et Manuel Cornejo Chaparro (éd.), Por donde hay soplo. Estudios amazónicos en los países andinos, IFEA, Lima, p. 185-216.

2016 «How much for a song? The culture of calculation and the calculation of culture », in Marc Brightman, Carlos Fausto et Vanessa Grotti, Ownership 
and nurture. Studies in native Amazonian property relations, Berghahn, New York, p. 133-155.

Francisco José

2012 Ceia, cânticos e batalha tribal fazem parte de ritual espiritual dos Enawenê. Equipe do Globo Repórter acompanha a impressionante ceia dos espíritos [vidéo], Globo Repórter, $8 \mathrm{~min}$, http://g1.globo.com/globo-reporter/noticia/2012/06/ceia-canticos-e-batalha-tribal-fazem-parte-de-ritual-espiritualdos-enawene.html, consulté le 23/10/17.

Ginsburg Faye

1991 «Indigenous media: Faustian contract or global village? », Cultural Anthropology, 6 (1), p. 92-112.

GoRDON Cesar

2006 Economia selvagem: ritual e mercadoria entre of índios Xikrin-Mebêngôkre, UNESP, São Paulo.

GRAHAM Laura

2012 « Image and instrumentality in a Xavante politics of existential recognition. The public outreach work of Ete'nhiritipa Pimentel Barbosa ", American Ethnologist, 32 (4), p. 622-641.

Graham Laura R. et H. Glenn Penny (éd.)

2014 Performing Indigeneity. Global histories and contemporary experiences, University of Nebraska Press, Lincoln.

GuIRAUD Serge

2011 Bero hoky mahadu, le peuple du grand fleuve [vidéo], Jabiru Prod/Iny karaja/ MHNT/LESC-EREA, 37 min.

2012 Ritxoko [vidéo], Jabiru Prod/Iny karaja/MHNT/LESC-EREA, $11 \mathrm{~min}$.

Hugh-Jones Stephen

2010 «Entre l'image et l'écrit: la politique tukano de patrimonialisation en Amazonie », Cahiers des Amériques latines, 63-64, p. 195-227.

JACKSON Jean E. et Kay B. WARREN

2005 «Indigenous movements in Latin America, 1992-2004: controversies, ironies, new directions », Annual Review of Anthropology, 34, p. 549-573.

JAKUBASZKO Andrea

2010 Dossiê Iphan - Yaokwa. Povo Enawene Nawe, Iphan, Brasília, http://portal. iphan.gov.br/uploads/ckfinder/arquivos/Dossie_Yaokwa.pdf.pdf, consulté le 23/10/2017.

LÉONARDELLI Sandrine

2005 Les jeux amazones [vidéo], ZED, $52 \mathrm{~min}$.

LisBôA Thomaz de Aquino

1985 Os Enauenê-Nauê: primeiros contatos, Loyola, São Paulo.

MacDougall David

1987 «Media Friend or Media Foe? », Visual Anthropology, 1 (1), p. 54-58.

Morgado Paula

2014 « Cinéma amérindien brésilien et utilisation du cyberspace. Pour qui?», Anthrovision [en ligne], 2 (2), http://anthrovision.revues.org/1448, consulté le $23 / 10 / 2017$. 
MYers Fred R.

2014 «Showing too much or too little: Predicaments of painting indigenous presence in Central Australia », in Laura R. Graham et H. Glenn Penny, Performing indigeneity. Global histories and contemporary experiences, University of Nebraska Press, Lincoln, p. 351-390.

Nahum-Claudel Chloé

2012 «Enawene-nawe "potlatch against the state" », Social Anthropology, 20 (4), p. 444-457.

2016 «The to and fro of documents: vying for recognition in Enawenê-nawê dealings with the Brazilian state », Journal of Latin American and Caribbean Anthropology, 21 (3), p. 478-496.

2017 Vital diplomacy. The ritual everyday on a dammed river in Amazonia, Berghahn, New York.

PÉTESCH Nathalie

2000 La pirogue de sable. Pérennité cosmique et mutation sociale chez les Karajá du Brésil central, Peeters, Paris.

2011 «Entre la flûte sacrée et le trophée de guerre: le masque karajá d'Amazonie brésilienne ", in Jean-Pierre Goulard et Dimitri Karadimas (éd.), Masques des hommes, visages des dieux, CNRS Éditions, Paris, p. 53-78.

Ramos Alcida

1994 « The Hyperreal Indian », Critique of Anthropology, 14 (2), p. 153-171.

1998 Indigenism. Ethnic politics in Brazil, University of Wisconsin Press, Madison. SoARes Nunes Eduardo

2009 «A cruz e o itxe(k)ó: mestiçagem, mistura e relação entre os Karajá de Buridina », mémoire de licence, Departamento de Antropologia, Instituto de Ciências Sociais, Universidade de Brasília, Brasília.

TURNER Terence

1991 «The social dynamics of video media in an Indigenous society. The cultural meaning and the personal politics of video-making in Kayapo communities », Visual Anthropology Review, 7 (2), p. 68-76.

1992 «Defiant images: the Kayapo appropriation of video », Anthropology Today, $8(6)$, p. 5-16.

VALADÃo Virgínia

1995 Yãkwá, o banquete dos espíritos [vidéo], Vídeo nas Aldeais, 54 min.

WEINER James F.

1997 « Televisualist anthropology: representation, aesthetics, politics », Current Anthropology, 38 (2), p. 197-235.

YvineC Cédric

2011 «Les monuments lyriques des Suruí du Rondônia (Amazonie méridionale): chants, événements et savoirs ", thèse de doctorat en ethnologie et anthropologie sociale, EHESS, Paris. 